NBER WORKING PAPER SERIES

LONG-RUN TRENDS IN THE ECONOMIC ACTIVITY OF OLDER PEOPLE IN THE UK

James Banks

Carl Emmerson

Gemma Tetlow

Working Paper 24606

http://www.nber.org/papers/w24606

\author{
NATIONAL BUREAU OF ECONOMIC RESEARCH \\ 1050 Massachusetts Avenue \\ Cambridge, MA 02138 \\ May 2018
}

This paper is part of the National Bureau of Economic Research's International Social Security (ISS) Project, which is supported by the National Institute on Aging (grant P01 AG012810). The authors are grateful to the other participants of that project for useful comments and advice. We are grateful to the ESRC-funded Centre for the Microeconomic Analysis of Public Policy at IFS (grant number RES-544-28-5001) for providing funding for this project. We are also grateful to Richard Blundell for useful comments. Data from the Labour Force Survey (LFS) were made available by the UK Data Archive. Responsibility for interpretation of the data, as well as for any errors, is the authors' alone. The views expressed herein are those of the authors and do not necessarily reflect the views of the National Bureau of Economic Research.

At least one co-author has disclosed a financial relationship of potential relevance for this research. Further information is available online at http://www.nber.org/papers/w24606.ack

NBER working papers are circulated for discussion and comment purposes. They have not been peer-reviewed or been subject to the review by the NBER Board of Directors that accompanies official NBER publications.

(C) 2018 by James Banks, Carl Emmerson, and Gemma Tetlow. All rights reserved. Short sections of text, not to exceed two paragraphs, may be quoted without explicit permission provided that full credit, including $\odot$ notice, is given to the source. 
Long-run Trends in the Economic Activity of Older People in the UK

James Banks, Carl Emmerson, and Gemma Tetlow

NBER Working Paper No. 24606

May 2018

JEL No. H55,J26

\begin{abstract} formal qualifications, have subsequently acquired some. particularly strong.

James Banks

Arthur Lewis Building-3.020

School of Social Sciences

The University of Manchester

Manchester M13 9PL

United Kingdom

and Institute for Fiscal Studies

j.banks@ifs.org.uk

Carl Emmerson

Institute for Fiscal Studies

7 Ridgemount Street

London WC1E 7AE ENGLAND

cemmerson@ifs.org.uk

Gemma Tetlow

Institute for Government

2 Carlton Gardens

London SW1Y 5AA

United-Kingdom

gemma.tetlow@gmail.com
\end{abstract}

We document employment rates of older men and women in the UK over the last forty years. In both cases growth in employment since the mid 1990s has been stronger than for younger age groups. On average, older men are still less likely to be in work than they were in the mid 1970s although this is not true for those with low education. We highlight issues with using years of schooling as a measure of educational achievement for analysing labour market trends at older ages, not least because a large proportion of men who left school at young ages without any

Reforms - such as the abolition of the earnings test and rises in the female State Pension Age, have pushed up employment rates. But other factors - such as the shift from defined benefit to defined contribution pensions being offered by private sector employers and the growth in employment rates at younger ages among successive cohorts of women - are also important. We discuss the role of other cohort and economy-wide trends, highlighting that the proportion of older men and women employed in professional, managerial and technical occupations has been 


\title{
Long-run trends in the economic activity of older people in the UK
}

\author{
James Banks, Carl Emmerson and Gemma Tetlow ${ }^{1}$
}

\section{Introduction}

Between the mid 1970s and the mid 1990s the employment rate of men approaching and just above age 65, the current State Pension Age for men, fell dramatically. Since then these employment rates have recovered somewhat, but they still remain someway below the levels seen forty years earlier. Employment rates of older women were relatively stable over the second half of the 1970s and first half of the 1980s but have risen sharply since then and are now at record levels. The net effect of these two offsetting trends has been that aggregate employment rates of 55 to 74 year olds are only now broadly comparable to the levels observed in the mid 1970s, albeit with a somewhat different composition across age/sex groups and having displayed a marked U-shaped trend in the intervening period.

In this paper we present and examine these trends in employment rates of men and women in detail. We document the extent that they are associated with changes in education levels, as opposed to changes in employment rates within education level, and how they relate to changing employment rates at younger ages of successive birth cohorts - with these also broken down by education level. For the period since the mid-1990s we compare trends in employment of older men and women in different occupations to those seen among younger men and women, and also describe how wage growth among older workers has, on average, compared to that seen among younger workers.

All of the data in this paper are taken from the UK Labour Force Survey (LFS). We have data biennially from 1975 to 1981 (inclusive), and then for each single year from 1983 to 2015 (inclusive). These data cover England, Scotland, Wales and Northern Ireland. The questionnaire contains extensive detail on the labour market activity of respondents and, for a household survey, it has a large sample size; an average of just below 400,000 individuals are observed per year (with a smaller sample size prior to 1992 and a larger sample size from 1992 onwards). The key information we use are age, sex, employment status, occupation and wages.

The headline trends in employment rates, by age, over the forty years from 1975 are shown for men in Figure 1.1, and for women in Figure 1.2. Looking first at men, employment rates fell for all age groups between 1975 and the mid 1990s and rose thereafter, with the $U$ shape in employment rates among men aged 50 and over - and in particular among those aged between 55 and 69 - being

\footnotetext{
${ }^{1}$ This paper is part of the National Bureau of Economic Research's International Social Security (ISS) Project, which is supported by the National Institute on Aging (grant P01 AG012810). The authors are grateful to the other participants of that project for useful comments and advice. We are grateful to the ESRC-funded Centre for the Microeconomic Analysis of Public Policy at IFS (grant number RES-544-28-5001) for providing funding for this project. We are also grateful to Richard Blundell for useful comments. Data from the Labour Force Survey (LFS) were made available by the UK Data Archive. Responsibility for interpretation of the data, as well as for any errors, is the authors' alone.
} 
more noticeable than that of younger men. By 2015, while the employment rates of 65 to 74 year old men were greater than they were forty years earlier, among younger age groups they were still below their mid 1970s level, with this being especially true of men aged 55 to 59 and 60 to 64 .

Figure 1.1 Employment rates of men, by age band, 1975-2015

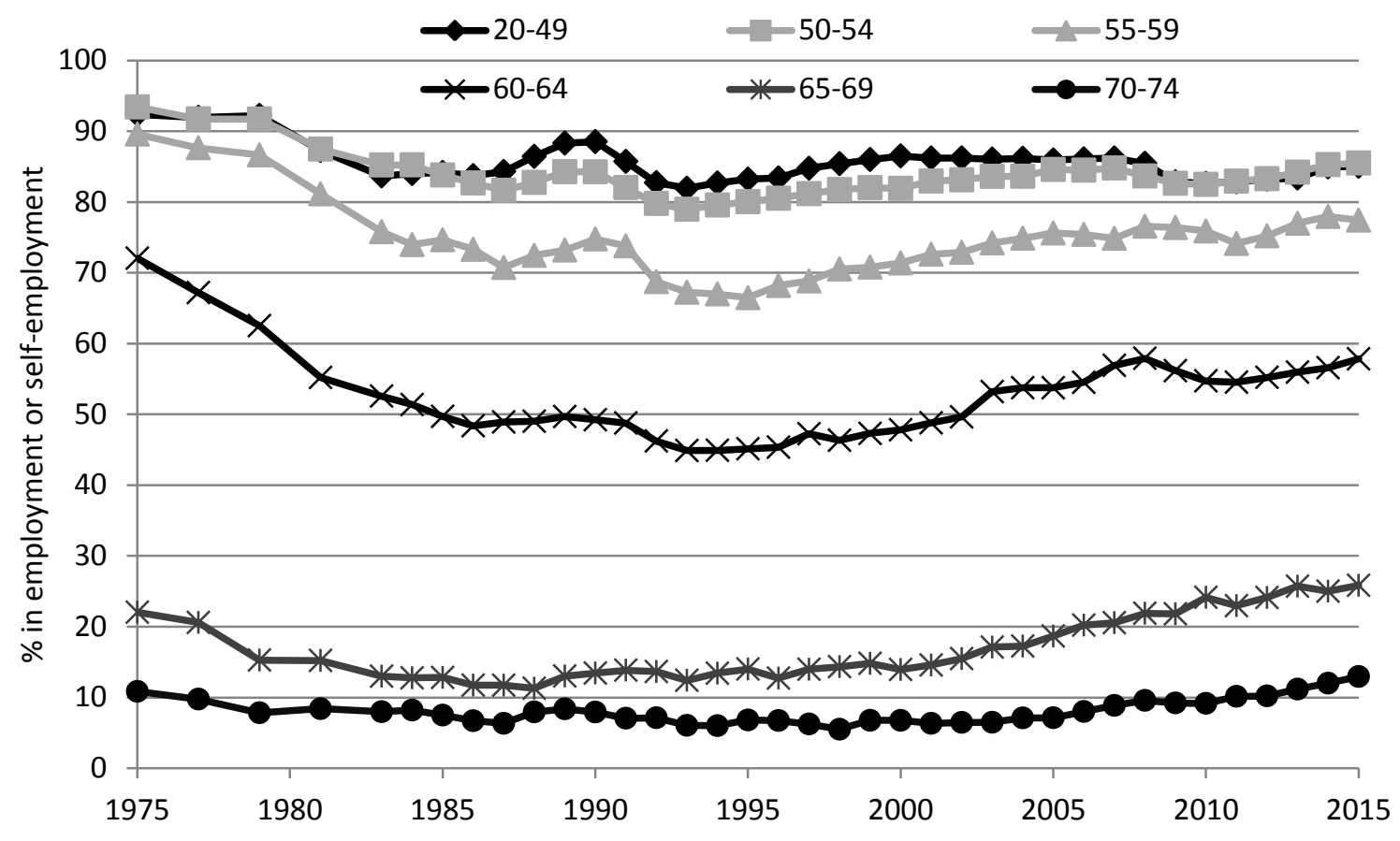

Source: Labour Force Survey.

A very different pattern over time is seen among women in Figure 1.2. Between 1975 and the mid 1980 s employment rates within each age group were generally relatively stable, although there was some fall among women aged 60 to 69 . Since then employment rates of women have grown strongly, and by 2015 the employment rate within each age group was higher than at any point in the previous forty years. Indeed in 2015 the employment rates among women aged 55 to 59, and those aged 60 to 64, are considerably higher than those seen at any point previously. 
Figure 1.2 Employment rates of women, by age band, 1975-2015

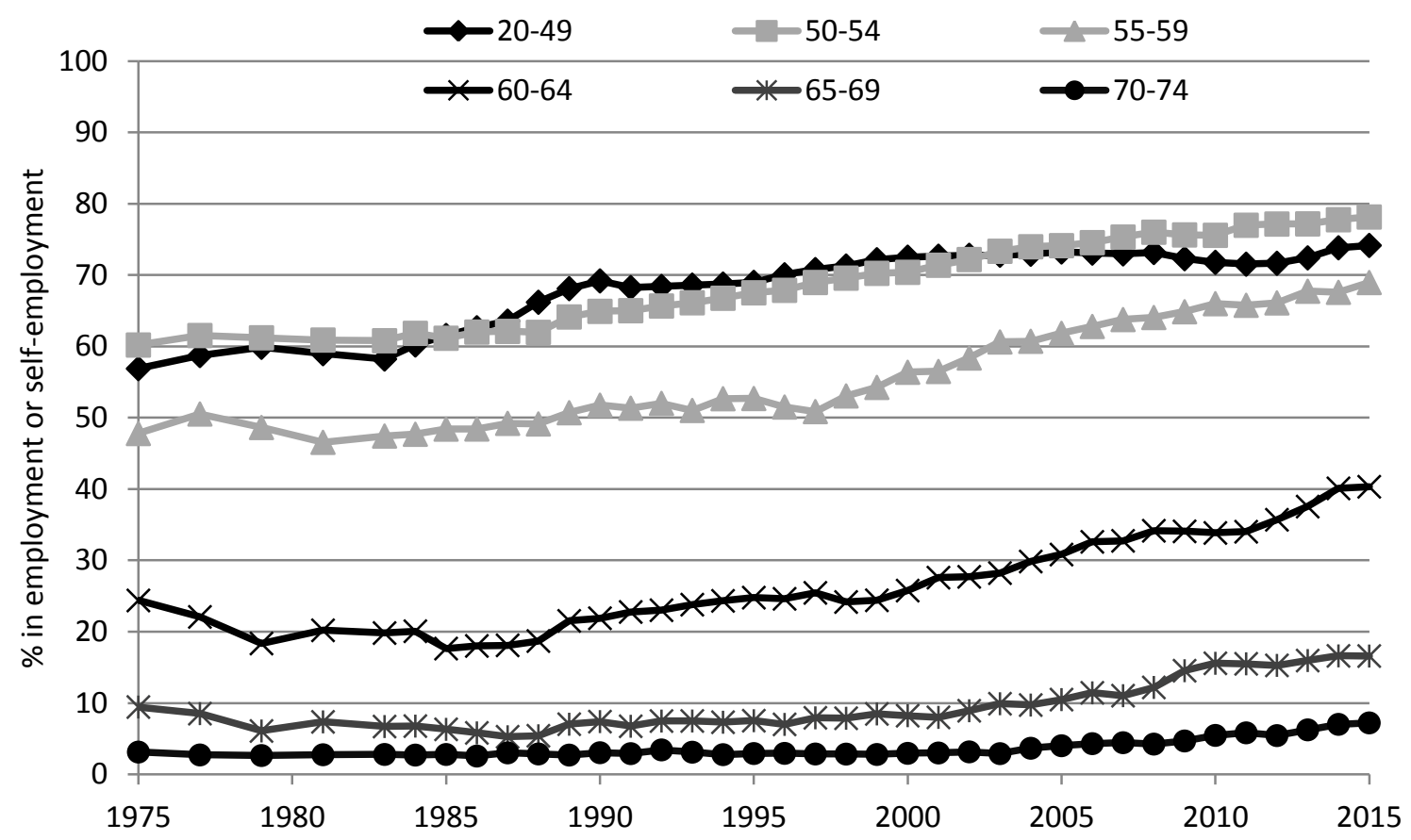

Source: Labour Force Survey.

In part the growth in employment rates of older men and women over the twenty years since the mid 1990s has occurred alongside growth in the employment rate of younger individuals. But the growth in employment rates of older individuals has been stronger than that of younger individuals over this period. This is in contrast to twenty years from the mid 1970s to the mid 1990s (and the first decade of this period in particular) where employment growth was lower among older individuals than younger individuals.

This relative employment growth of old to younger ages is shown in Table 1.1. In 1975 the employment rate of men aged 50 to 64 was $93 \%$ of the employment rate of men aged 20 to 49 , while the equivalent figure for women was $78 \%$. By 1995 these ratios had fallen to $78 \%$ and $72 \%$ respectively. These ratios for both men and women grew over the subsequent twenty years, such that for men the employment rate of the older group reached $88 \%$ of that of the younger group, whereas among women the employment rate of the older group reached $86 \%$ of that of the younger group. Overall this means that by 2015 the employment rate of older men, relative to that of younger men, was still lower than it was forty years earlier in 1975. In contrast the employment rate of older women, relative to that of younger women, was greater than it was forty years earlier. A further consequence of this difference between trends for each gender is that, for the first time the relative employment rates of old to younger adults are now comparable for men and women. 
Table 1.1. Employment rate of 50-64 year olds compared to that of 20-49 year olds, by sex, selected years

\begin{tabular}{c|ccc|ccc}
\hline & \multicolumn{3}{|c|}{ Men } & \multicolumn{3}{c}{ Women } \\
& \multicolumn{2}{|c|}{ Employment rate } & Ratio & \multicolumn{2}{c}{ Employment rate } & Ratio \\
& 20 to 49 & 50 to 64 & & 20 to 49 & 50 to 64 & \\
\hline 1975 & 92.4 & 85.5 & 0.93 & 56.9 & 44.5 & 0.78 \\
1985 & 84.2 & 69.5 & 0.83 & 61.5 & 41.8 & 0.68 \\
1995 & 83.2 & 65.0 & 0.78 & 69.0 & 49.5 & 0.72 \\
2005 & 85.9 & 72.4 & 0.84 & 73.3 & 56.9 & 0.78 \\
2015 & 85.0 & 74.8 & 0.88 & 74.2 & 64.0 & 0.86 \\
\hline
\end{tabular}

Source: Labour Force Survey.

\section{Background context}

This section sets out some of the background context relating to the employment rates of older individuals over the time period 2010 to 2015 that were presented in the previous section. We begin by discussing economic factors - both the macroeconomic situation and changes in the policy environment. We then turn to brief discussions of trends in the education and health of those approaching, or around, retirement age. These three sets of trends combined have led to secular cohort effects in terms of the characteristics of those at retirement age, and such trends are important to consider when we look at employment rates by age among different birth cohorts, and also motivate our analysis of cohort trends split by education which follows in section 3 .

\subsection{Macroeconomic and microeconomic policy background}

One key factor to bear in mind throughout is the performance of the UK economy over this period. Deep recessions were experienced in the mid 1970s, early 1980s, early 1990s and late 2000s. In contrast the second half of the 1980s was a period of very strong growth (with the four years from $1985 q 1$ to $1989 q 1$ seeing average annual growth of 4.5\%), while the period from the start of 1993 through to the start of 2008 (the eve of the financial crisis) being one of strong and stable growth (averaging 2.9\% per year from 1993q1 to 2008q1). These up-and-downs of economic performance were reflected in the employment rates shown in the previous section: for example among 20 to 49 year old men (Figure 1.1) the employment rate fell during the recession of the early 1980s, grew strongly during the boom of the late 1980s before falling again in the early 1990 s recession. It then climbed throughout the period from 1993 through to the end of the 1990s before falling again during the great recession of the late 2000 s.

In addition to these macroeconomic trends and cycles, however, the UK has been characterised by a huge amount of policy reform. The key sources of income, other than earnings, for older individuals are: state pensions; other state benefits targeted at those on lower incomes or those in poor health; and private sources of income including private pensions. Eligibility - or potential eligibility - for many of these can affect incentives to retire. And these sources of income have been subject to 
many reforms. In some cases reform has been announcements of future policies to be gradually phased in, in others reforms have taken effect immediately. Much has directly affected the incentives to work for those who qualify for the various benefit programmes, and in many cases this was by design. In what follows we briefly describe the evolving policy context, focussing just on reforms that might be expected to have had impacts on the labour market outcomes of older individuals. The timeline for these reforms is summarised in Table 1.2 but further details in each dimension are given in the subsections below (a fully comprehensive description of state pension reforms over the period 1948 to 2010 can be found in Bozio, et al (2010) while Crawford, et al (2013) discuss more recent changes).

Table 1.2 Key reform dates for policies affecting labour market incentives for older workers.

\begin{tabular}{|c|c|c|c|}
\hline Year & State pensions & Other state benefits & Private retirement income \\
\hline 1975 & Increasing generosity & & \\
\hline 1981 & $\begin{array}{l}\text { Indexing made less } \\
\text { generous }\end{array}$ & & \\
\hline 1986 & Declining generosity & & \\
\hline 1988 & & & $\begin{array}{l}\text { Introduction of private personal } \\
\text { pensions (DC) }\end{array}$ \\
\hline 1989 & $\begin{array}{l}\text { Removal of earnings } \\
\text { test }\end{array}$ & & \\
\hline 1995 & Declining generosity & $\begin{array}{l}\text { Reduced generosity, } \\
\text { increased stringency }\end{array}$ & \\
\hline 1999 & & $\begin{array}{l}\text { Other benefits for women } \\
\text { over SPA made more } \\
\text { generous }\end{array}$ & \\
\hline 2001 & & $\begin{array}{l}\text { Reduced generosity, } \\
\text { increased stringency }\end{array}$ & \\
\hline 2002 & Increasing generosity & & \\
\hline 2003 & & $\begin{array}{l}\text { Means-tested pensioner } \\
\text { benefits made more } \\
\text { generous }\end{array}$ & \\
\hline 2006 & & & $\begin{array}{l}\text { DB plans less restrictive in terms } \\
\text { of drawing income whilst } \\
\text { continuing to work }\end{array}$ \\
\hline 2008 & & $\begin{array}{l}\text { Reduced generosity, } \\
\text { increased incentives to move } \\
\text { back into work }\end{array}$ & \\
\hline 2010 & $\begin{array}{l}\text { Rise in female SPA } \\
\text { begins; increasing } \\
\text { coverage for some; } \\
\text { indexation made more } \\
\text { generous }\end{array}$ & & \\
\hline 2016 & $\begin{array}{l}\text { New state pension } \\
\text { introduced: more } \\
\text { generous in near-term, } \\
\text { less generous in long- } \\
\text { run }\end{array}$ & & \\
\hline
\end{tabular}




\section{State pensions}

In terms of marginal financial incentives to retire the key reform to state pensions was the abolition of the earnings test in 1989 . $^{2}$ Prior to that date receipt of the state pension could be reduced if the individual was also earning, whereas since then individuals could continue in paid work and still receive an unreduced state pension. Some may also find that remaining in paid work up to the state pension age boosts the value of their accrued state pension, with this effect likely to be stronger among women in the past when more years of contributions were required to qualify for a full state pension and when fewer activities other than being in paid work were counted as a contribution.

The age at which individuals can receive their state pension - the state pension age - may also affect retirement behaviour if, for example, it provides a signal about the appropriate age to leave the labour market. Between 1948 and April 2010 this was 65 for men and 60 for women. Since April 2010 the state pension age for women has been rising such that it is planned to be equalised to the male state pension age of 65 in November 2018. The state pension ages of men and women are then due to be increased together, so that they reach age 66 in October 2020. Cribb, Emmerson and Tetlow (2016) showed that the rise in the female state pension age from 60 to 62, which occurred between April 2010 and April 2014, boosted employment rates among women aged 60 and 61 by 6.3 percentage points. Some descriptive evidence of this is provided in Section 3 below.

State pension reforms in 1975 and 2000 made the state pension system significantly more generous, while intermediate reforms - in 1986 and 1995 - made it substantially less generous. These changes have generated differences in the state pension entitlements across years of birth which, in turn, may have affected retirement ages. There has also been variation within individuals born in the same year: the state pension system has been increasingly generous to low earners and some groups not in paid work in more recent years, while the generosity of the system to higher earners peaked among those reaching state pension age around 2000. More recent changes - that came into effect from April 2016 - will make the state pension more generous for many individuals (such as the self-employed) but less generous for most individuals over the longer-term.

\section{Other state benefits}

Other state benefits may also affect retirement behaviour with potentially the most important being out-of-work disability benefits for those deemed to be in poor health. The amount paid to individuals is flat rate - i.e. it does not vary with past earnings, and for those who do not meet the contribution requirements it is means-tested. This means that for those who could otherwise earn average, or above average, amounts the financial incentive to leave paid work in order to receive these disability benefits is relatively weak. But lower earners whose health means that they are able to qualify for these benefits if they were out-of-work may face relatively strong financial inventive to leave the labour market (Banks, Emmerson and Tetlow, 2016).

There have been several reforms to these benefits - in particular in 1995, 2001 and 2008 - all with the intention of reducing the numbers receiving them. The first two of these reforms focussed on reducing the in-flow onto these benefits, while the third also strived to increase the off-flow from benefits into paid work. Trends in receipt of benefits is documented in Banks, Blundell and

\footnotetext{
${ }^{2}$ For details - and an assessment - see Disney and Smith (2002).
} 
Emmerson (2015) who show that receipt is less related to age, and more related to education levels, then it was twenty years ago.

Other out-of-work benefits, which are targeted towards those on lower-incomes, also reduce the financial incentive to remain in paid work, with this again being particularly true of lower wage workers. These are more generous to those who are aged above the female state pension age - and those who have a partner aged above the female state pension age - (regardless of whether they are a man or a woman) then they are for younger individuals. For example in 2015-16 the maximum award of pension credit (for a single person without any disabilities) was $f 151.20$ per week, whereas for a single person aged over 25 the maximum rate of Jobseeker's Allowance was $f 73.10$ per week. In addition the latter would require the recipient to seek work and attend work focussed interviews, whereas Pension Credit is paid unconditionally. For those aged over the female state pension age these benefits have also been made relatively more generous over time, in particular in 1999 and in 2003.

\section{Private income}

By far the most important source of private income in retirement is income from private pensions: the relatively low level of state pension (particularly for those 'contracted-out' of the state earnings related pension system) has meant that private pensions have always played an important role in providing retirement income. Since 1988 defined contribution pensions have become more prevalent among private sector employees, as coverage of defined benefit pensions has declined sharply. In contrast among public sector workers defined benefit pension coverage remains very high.

These different types of pensions typically have very different incentives to start drawing at different ages. Defined contribution pensions would typically be expected to rise in value. Defined benefit pensions, in contrast, typically provide a strong incentive to draw the pension at the normal pension age as they often impose an actuarial reduction if they are drawn before this age but do not offer an actuarial increase for delayed drawing. Historically the normal pension age is often 60 for public sector employees and 65 for private sector employees (and for many who joined public sector schemes after around 2005).

In individually-arranged defined contribution pensions any incentive to draw the pension at a particular point in time would not translate into an incentive to leave paid work. In contrast up until April 2006 for those in employer provided private pensions any incentive to draw a private pension translated into an incentive to leave paid work (or at very least to move employer) since up until that point it was not possible to draw a private pension from an employer and continue to work for that employer. But since April 2006 this restriction has been lifted and, if they wish, employees can draw a pension and continue to work for that same employer.

Other

Two other important reforms, which do not fit naturally into Table 1.2 or the subsections above, also took place over this period. First, compulsory retirement ages below 65 were outlawed from October 2006, and then any compulsory retirement ages regardless of age were outlawed from October 2011. Second, public service pensions have been reformed. The normal pension age in 
public sector plans has been increased (often from 60 to 65), with this first affecting new entrants to these schemes in the mid to late 2000s (with the exact date varying from scheme to scheme). Further increases, which were also applied to many existing members, will align it with the state pension age from the mid 2010s (but not for those already within ten years of their existing normal retirement age). Since April 2011 for deferred members, and those receiving these pensions, the indexation has been made less generous while from the mid 2010s they were moved from operating on a final salary basis to a career earnings basis (which changes to how earnings were uprated and the accrual rate at the same time, with the exact changes varying from scheme to scheme).

\subsection{Trends in education}

Regardless of how it is measured, education levels in the UK have been rising across successive birth cohorts and this has been particularly true for those cohorts reaching retirement age over the period since 1999. This section documents two possible measures of education levels - years of school and qualifications received - before documenting trends in employment rates among older individuals split by a measure of education and shown separately for men and women. In each case we have somewhat incomplete data over the full course of our period. Questions on age left full time education were only introduced to the LFS from 1984 onwards, and even then only for those under the State Pension Age or for those still in work if over State Pension Age. By choosing a reference age of 55 we are able to get data on years of education back to 1975 for men but only back to 1980 for women. Data on qualifications was introduced to the survey even later so in that dimension our series can only go back to 1983 and 1988 respectively.

The evolution of the distribution of school leaving ages over successive birth cohorts are shown for men in Figure 2.1 and for women in Figure 2.2. We choose to present these by the age at which the cohort reaches age 55 in order to provide a scale that is relevant to the consideration of the group entering the retirement window. In both figures it is very clear that those reaching age 55 in 1989 were much more likely to have remained in school beyond age 14 than those reaching age 55 a year earlier. This is due to a policy reform: the 1944 Education Act increased the school leaving age to 15 from April 1947. Those aged 55 in 1989 were born in 1934 and therefore turned age 14 in 1948 and were unable to leave school at this point. ${ }^{3}$ In a similar vein those reaching age 55 in 2013 are much less likely to have left school at age 15 than those reaching age 55 one year earlier. This was driven by the school leaving age increasing to age 16 from September 1972, and those aged 55 in 2013 will have been born in 1958 and therefore were aged 15 in 1973 and (typically) unable to leave school at this point.

\footnotetext{
${ }^{3}$ A small fraction of children can still leave whilst one year 'younger' than the compulsory school leaving age since the school year ends in July and it is age on $1^{\text {st }}$ September that determines whether or not you need to start the next school year.
} 
Figure 2.1. Distribution of age of leaving full-time education, by cohort - men

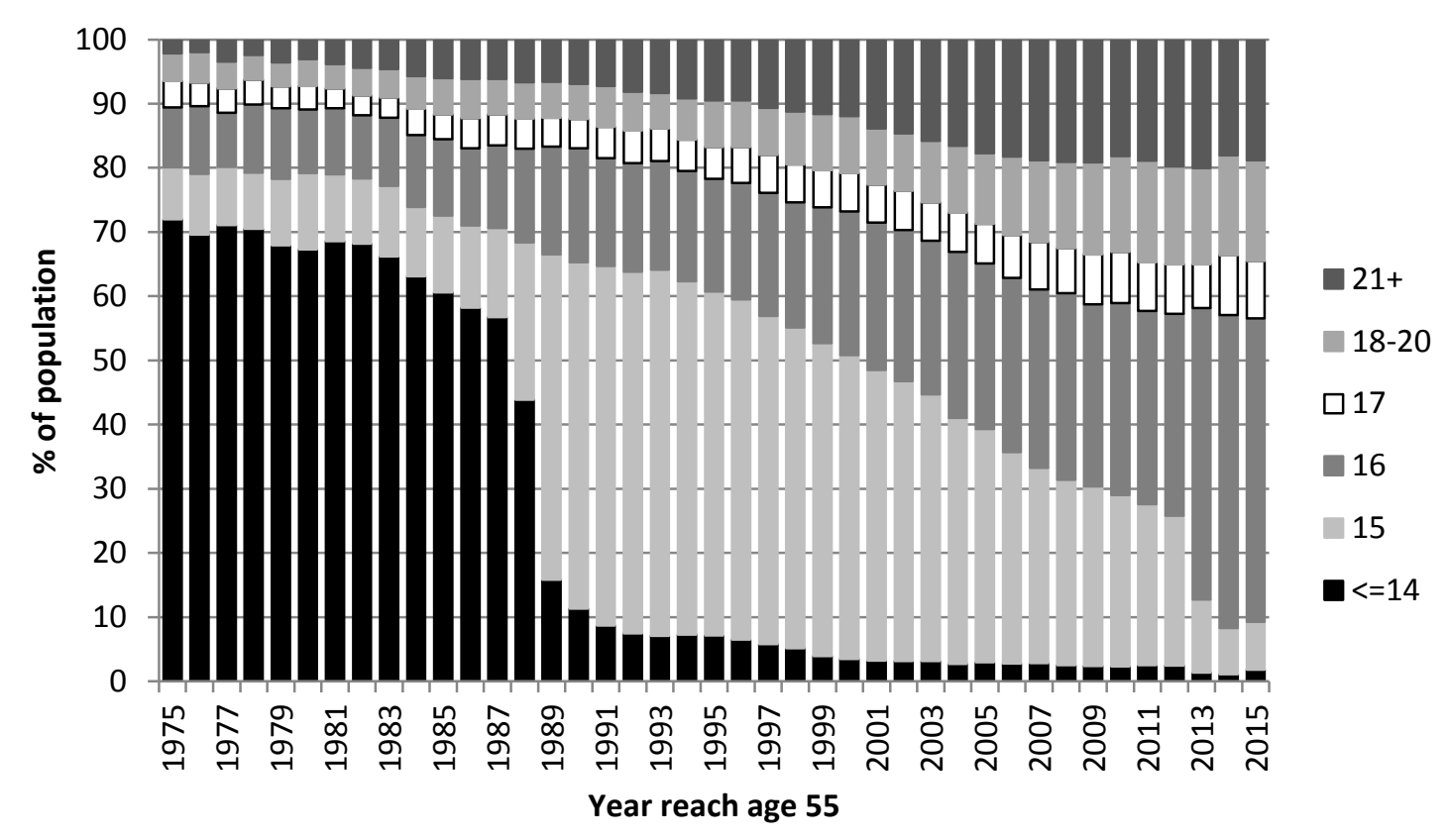

Source: Based on sample of all individuals aged 55 to 64 observed in the Labour Force Survey (1984-2015).

More generally there is a noticeable increase in the number of years of full-time education across cohorts over the period, with a general decline in the share of men and women leaving school at or before age 15 and general increase in the proportion leaving school after age 15. The shares leaving full time education at ages 18 to 20 , or at ages 21 and over have also increased substantially 
Figure 2.2. Distribution of age of leaving full-time education, by cohort - women

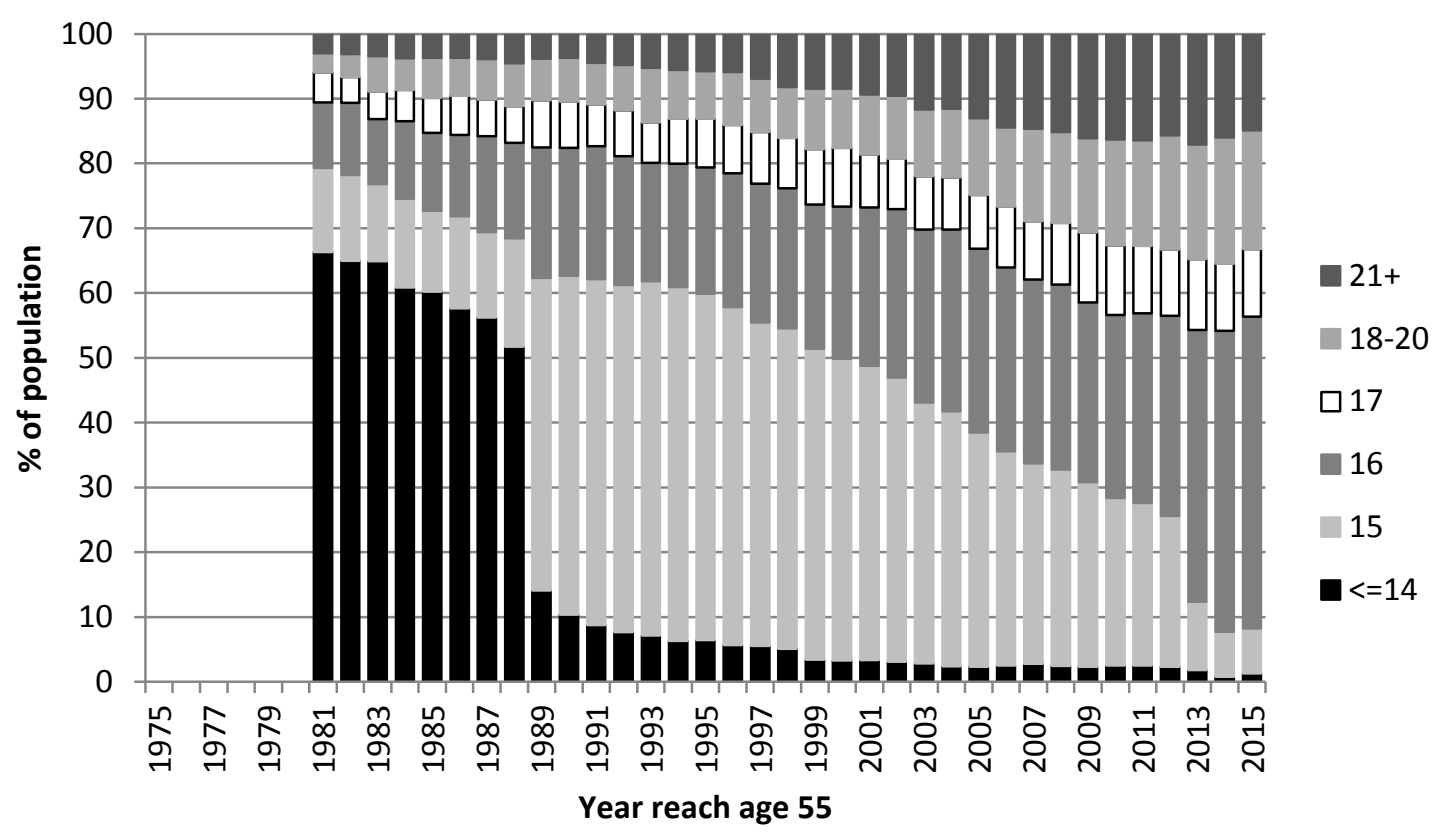

Source: Based on sample of all individuals aged 55 to 59 observed in the Labour Force Survey (1984-2015).

An alternative measure of educational attainment is to look at qualifications received rather than years of education attended. Trends in qualifications can be looked at using the LFS, which has recorded these on a consistent basis since 1992. For this analysis we again look at men aged between 55 and 64 and women aged between 55 and 59 - i.e. the same age ranges covered in the previous two figures which examined school leaving ages (although the data start in 1992 rather than in 1984). We then take just the group who left school at or below the compulsory school leaving age - which we can think of as a "low" education group - and show how their levels of qualifications achieved have varied over time. This group is of particular interest as these are, by definition, the group whose qualifications are more likely to be affected by increases in the school leaving age and they may also be the group where obtaining some kind of further qualification after leaving formal education may be most prevalent.

The results are shown for men in Figure 2.3 and for women in Figure 2.4. Several things are apparent from the two figures. Firstly, among this group of "low education" men there has always been a sizeable group who report achieving the equivalent of A level qualifications or above - i.e.

qualifications equivalent to those that could typically be attained at age 18 among those who remained in school - despite the fact that these individuals reported leaving school at age 16 at the latest. Indeed among men who turned age 55 in 1983 the data show that around 30\% have the equivalent of $A$ level qualifications or above despite them having first left school at age 14 (or earlier).

Second, increases in the compulsory school leaving age did lead to a greater proportion of men and women receiving formal qualifications. This can be seen by the fall in the proportion of men with no qualification between those who were age 55 in 1983 and those who reached age 55 one year later, which coincided with those affected by the compulsory school leaving age rising from age 14 to 15 . Similarly a clear effect of the increase in the compulsory school leaving age from age 15 to 16 on 
qualifications can be seen in the proportion of both men and women with no qualifications falling between those reaching age 55 in 2011 and those reaching age 55 one year later.

Finally, of those who left school at the compulsory school leaving age a much larger proportion of women than men have no formal qualifications, although the gap between the two has been falling sharply over time. Between those reaching age 55 in 1988 and those reaching age 55 in 2011 (a period in which the compulsory school leaving age was 15 throughout) the proportion of men with no formal qualifications fell from $44 \%$ to $30 \%$, while over the same period the proportion of women with no formal qualifications fell from $78 \%$ to $44 \%$. So the gap between the two genders fell from 34 percentage points to 14 percentage points.

Figure 2.3. Distribution of qualification among men classified as having "low" education - by cohort

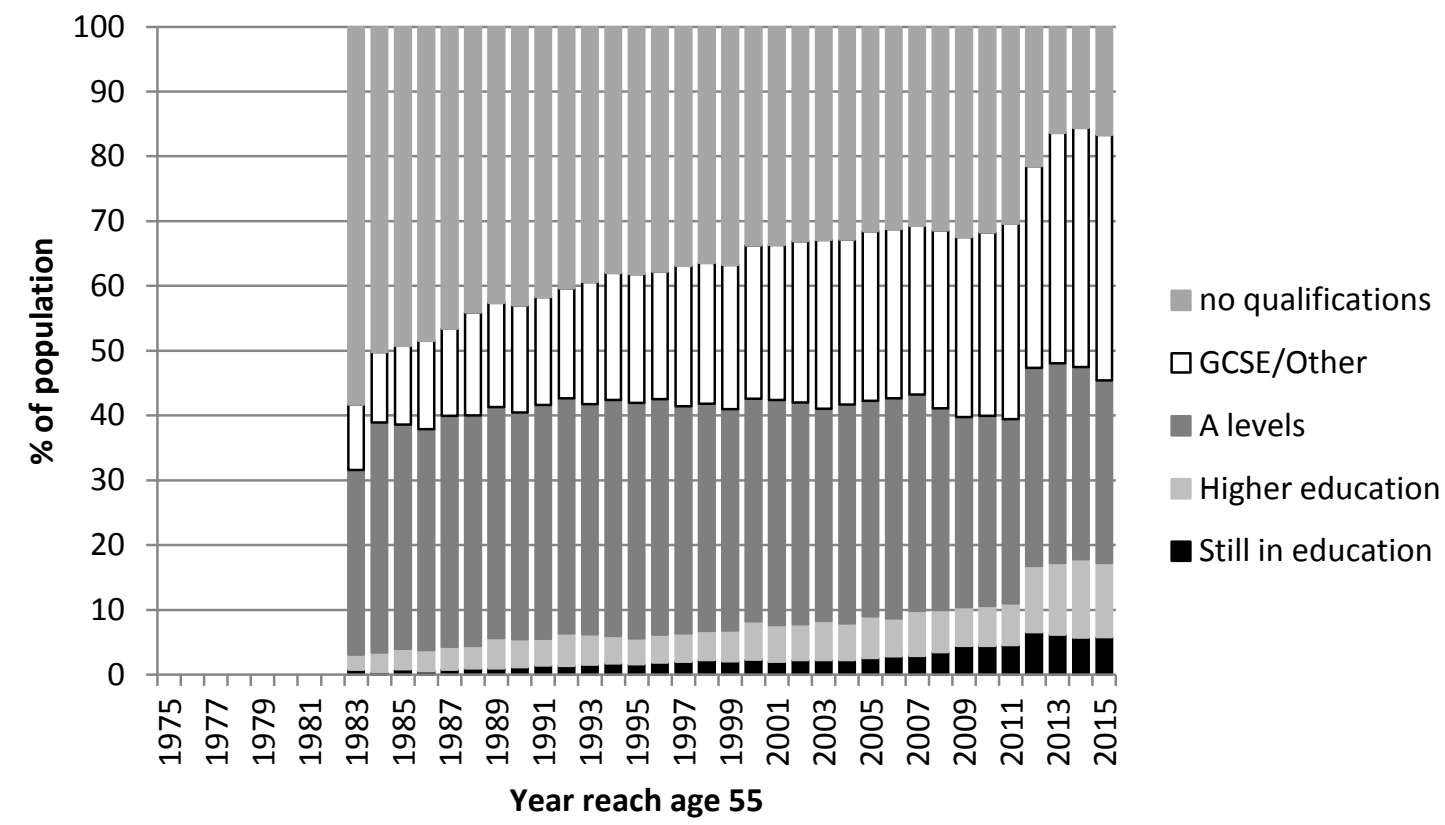

Source: Based on sample of all individuals aged 55 to 64 observed in the Labour Force Survey (1992-2015). 
Figure 2.4. Distribution of qualifications among women classified as having "low" education - by cohort

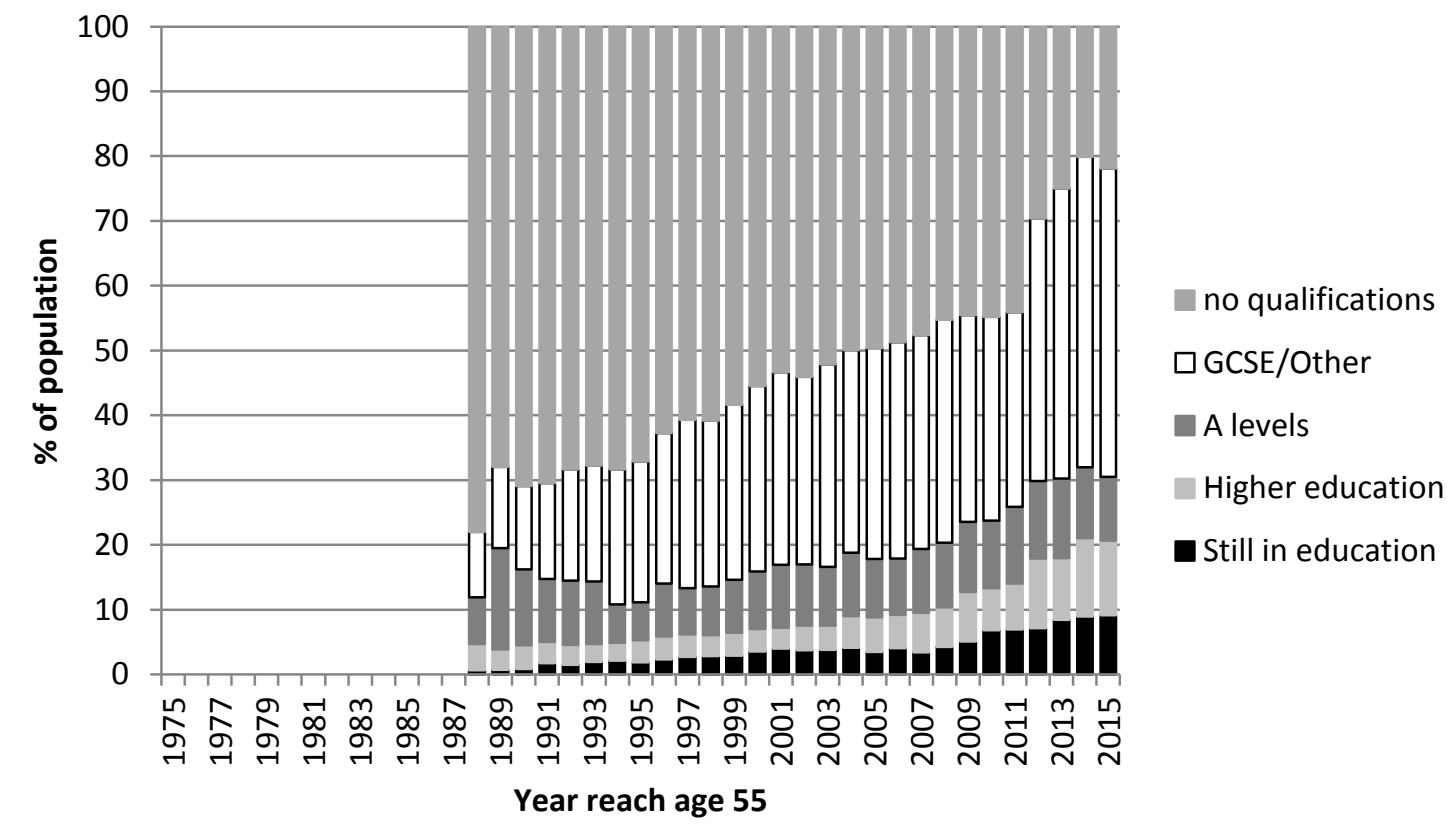

Source: Based on sample of all individuals aged 55 to 59 observed in the Labour Force Survey (1992-2015).

In the remainder of our analysis we present employment rates for a "low education" group defined as those who left continuous education at or below the compulsory school leaving age and a "high education" group who left continuous education at age 21 or over. (A middle group, comprising those who stayed in continuous education beyond the compulsory school leaving age but not until age 21 will be omitted from these splits.) The resulting education distribution as defined by this method, among men aged 55 to 64 and women aged 55 to 59, is shown for 1985, 1995, 2005 and 2015 in Figure 2.5. This shows that under our classification the proportion of men and women who are "high education" has been increasing while the proportion who are "low education" has been falling. For men this change is observed between all the years shown in Figure 2.5, whereas among women the big shift occurred between 1985 and 1995. 
Figure 2.5. Rising education levels of men aged 55 to 64 and women aged 55 to 59

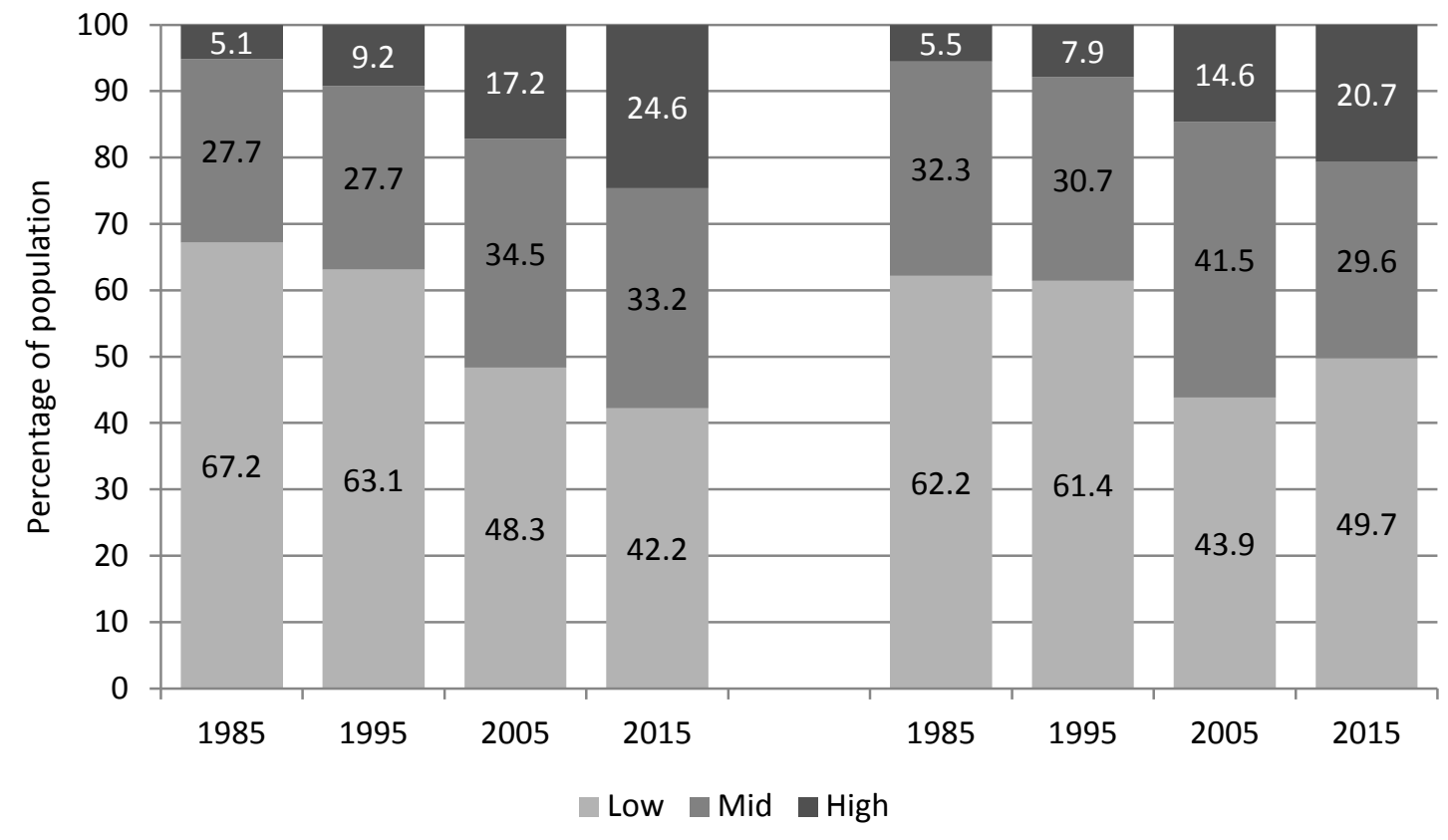

Source: Labour Force Survey.

This categorisation of education by years of schooling is fairly common in the UK, particularly in studies that involve analysis alongside other countries, since qualifications are not so easily comparable internationally. Broadly speaking, although the number of years of education may differ, it corresponds conceptually to the split of high school graduates, some college, and collegegraduates that is frequently used in US analysis. And it has the advantage, when using LFS data, of allowing us to cover the period from 1984 onwards. But there are some potential issues with this choice. First, the direct impact of increasing the compulsory school leaving age for our cohorts will be to increase the proportion of individuals classified as having "low education" within our sample. Second, as the proportion in the "high education" has increased it is possible that the meaning of "high education" in terms of the labour market could be changing over time. Third, as we have already shown there is a not inconsiderable (and increasing) proportion in the "low education" group who have some qualifications. A years-of-education based split is somewhat crude and cannot capture either the changing skills and qualifications of each group conditional on their years of schooling, nor any post-schooling qualifications (or changes in the rate at which these have been acquired by successive cohorts). On this last point, it is also worth noting that immigration, recall bias, changes to the survey and differential mortality would also be additional reasons why the qualifications of a cohort observed at later ages may differ from the degree to which that cohort reports their school leaving age. These effects may not be negligible and would, again, lead to a qualifications measure (subject to sufficient reporting quality) being superior in terms of corresponding to how the labour market and technological skills of the cohort may have been changing.

With these caveats in mind Figure 2.6 presents the employment rates of the "low education" and "high education" groups of older men and women over time. Among men employment rates of both education groups fell between 1984 and the mid 1990s and then rose over the subsequent twenty 
years. Despite this increase by 2015 the employment rate of "high education" older men was still below its level in 1984, while the employment rate of "low education" older men was some way above its mid 1980s level. So among men aged 55 to 64 the education gradient in employment is now less steep then it used to be. Among women aged 55 to 59 employment rates of those with "high education" and those with "low education" have increased between 1984 and 2015, such that among each group their employment rates are now at the same level as those seen among men aged 55 to 64 in the same education category.

Figure 2.6 Employment rate among men aged 55 to 64 and women aged 55 to 59 , by education

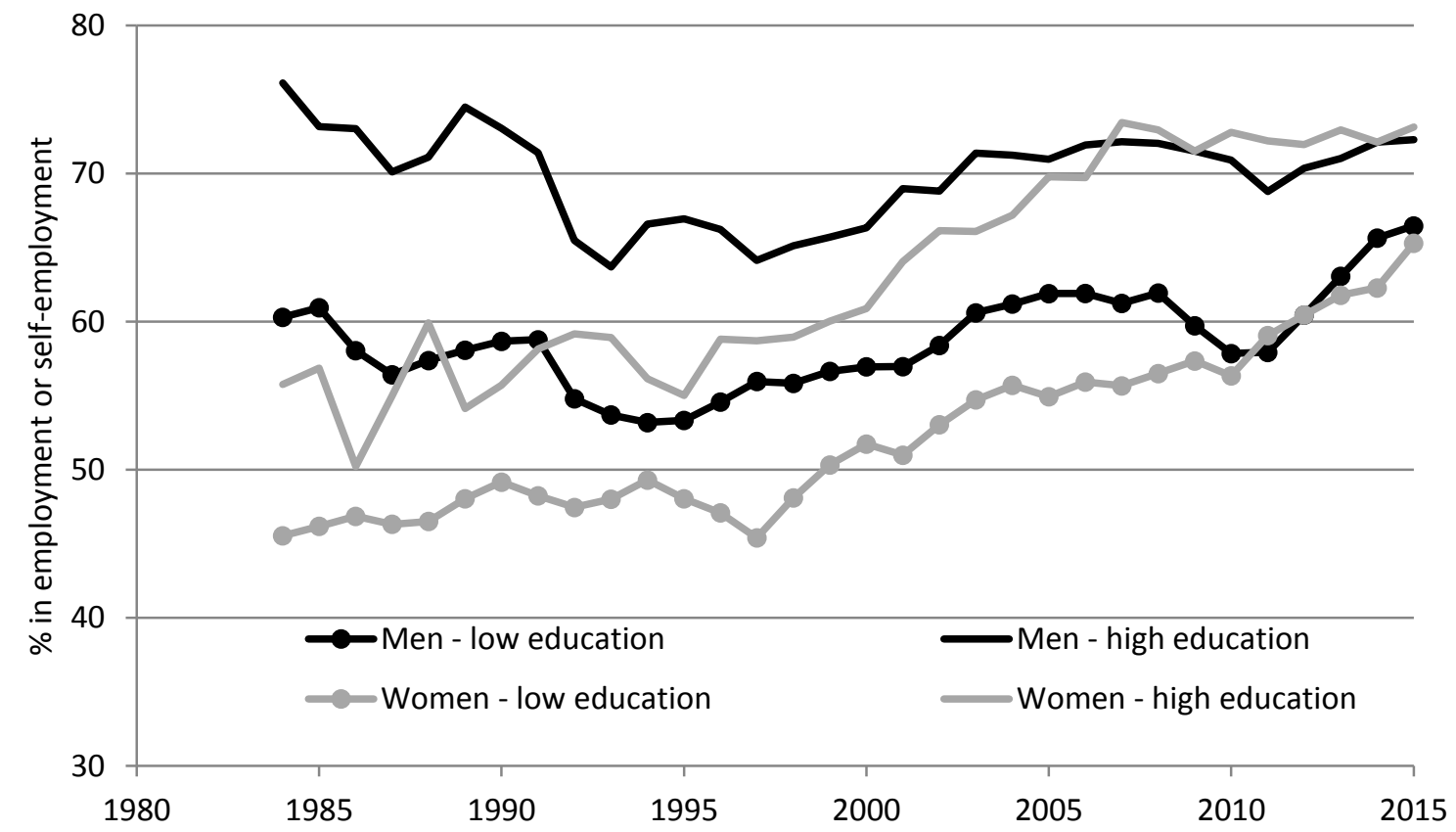

Source: Labour Force Survey.

The LFS data allow us to carry out a simple shift share analysis to decompose growth in employment among older individuals over the twenty years from 1995 and 2015 into that which is explained by greater levels of education (since, as shown in Figure 2.6, individuals with greater levels of education are more likely to be in employment and since, as shown in Figure 2.5, education levels have been increasing over time) and how much is explained by rising levels of employment within each education group.

Amongst men aged 55 to 64 employment rates rose by 11.9 percentage points between 1995 and 2015 , of which 2.3 percentage points would have occurred had employment rates conditional on education levels (as measured by years of schooling) remained unchanged at their 1995 rates. Amongst women aged 55 to 59 employment rates rose by 17.3 percentage points between 1995 and 2015 , of which only 0.8 percentage points would have occurred had employment rates conditional on education levels remained unchanged at their 1995 rates. This relatively small effect of rising education levels for women is in part because the increase in education - at least on our measure has not been as great over this period and, in addition, the gradient in employment by education in the mid 1990s was less steep for women than for men (as shown in Figure 2.6). 
If we look at the evolution of employment rates among older men and women and instead split by our measure of qualifications received (rather than years of schooling) then the decomposition comes out rather differently. Among men, 3.1 percentage points of the 11.9 percentage point increase in employment between 1995 and 2015 would have occurred just from the composition shift, had employment rates conditional on qualifications remained unchanged at their 1995 rates. This is slightly above the 2.3 percentage points reported above when doing the decomposition using years of schooling. Among women, of the 17.3 percentage points increase in employment over the twenty years from 19956.2 percentage points would have occurred had employment rates conditional on qualifications remained at the 1995 rates. This is much larger than the 0.8 percentage points reported above when doing the decomposition using years of schooling. This large difference is due to the proportion of women aged 55 with no qualifications falling sharply over this period (as shown in Figure 2.4) and the fact that employment rates among older women with no qualifications are much lower than employment rates among women with some qualifications.

\subsection{Trends in health}

Perhaps the other obvious secular trend occurring across cohorts in the last forty years that might be thought to be affecting labour market participation has been improvements in health and reductions in mortality. Consistently measured health data over our forty-year period do not exist in the UK so we are unable to document this in much detail. What is well-known is that life-expectancy at older ages has increased rapidly, even more so for males than for females, over the period. Whilst such a trend can be documented in many ways, each telling the same story, a simple indicator of the magnitude of this effect is given in Table 2.3 which presents life expectancy at age 60 which has risen by seven years for males and five years for females.

\section{Table 2.3}

Additional years life expectancy at age 60 (period basis); England and Wales

\begin{tabular}{|l|l|l|l|l|l|}
\hline & $1970-72$ & $1980-82$ & $1990-92$ & $2000-02$ & $2010-12$ \\
\hline Male & 15.4 & 16.4 & 17.9 & 19.9 & 22.4 \\
\hline Female & 20.0 & 20.9 & 22.1 & 23.3 & 25.2 \\
\hline
\end{tabular}

Source: Office for National Statistics, 2015, English Life Tables No. 17,

http://www.ons.gov.uk/ons/rel/lifetables/decennial-life-tables/english-life-tables--no-17--2010$\underline{12 / \text { stb-elt17.html }}$

In previous work we documented these late-life longevity and mortality trends in terms of the underlying one-year mortality probabilities at each age between 50 and 75 (Banks, Emmerson and Tetlow, 2017) and the large and rapid changes over the period were immediately apparent. Taking State Pension Age as a reference point, for example, for a 65 year old male these fell by a factor of three, from $3.4 \%$ in 1970 to $1.1 \%$ in 2015 and for a 60 year woman they fell by more than a factor of two from $2 \%$ to $0.8 \%$.

When it comes to understanding health as opposed to life-expectancy, the data in the UK are considerably more patchy, particularly before the mid 1990's and the advent of the Health Survey for England. Surveys with measures of population prevalence of disease or disability do not exist on a consistent basis over the period since 1975; the best information available comes from crude summary self-reported health measures, of the type that is available in many general purpose social 
surveys around the world. Figure 2.7, calculated using data from the General Household Survey, shows that such data only demonstrate a very mild improvement in health over the period and even this is only really apparent for women - who show an increase in the proportion reporting health as 'good' and a reduction in the proportion reporting health as 'fairly good'. Similar trends would be observed in the Health Survey for England which measures self-reported health on a more conventional five-point scale over the period 1991-2015.

Figure 2.7. Self-assessed health amongst 55-69 year olds, 1975-2015

Source: General Household Survey

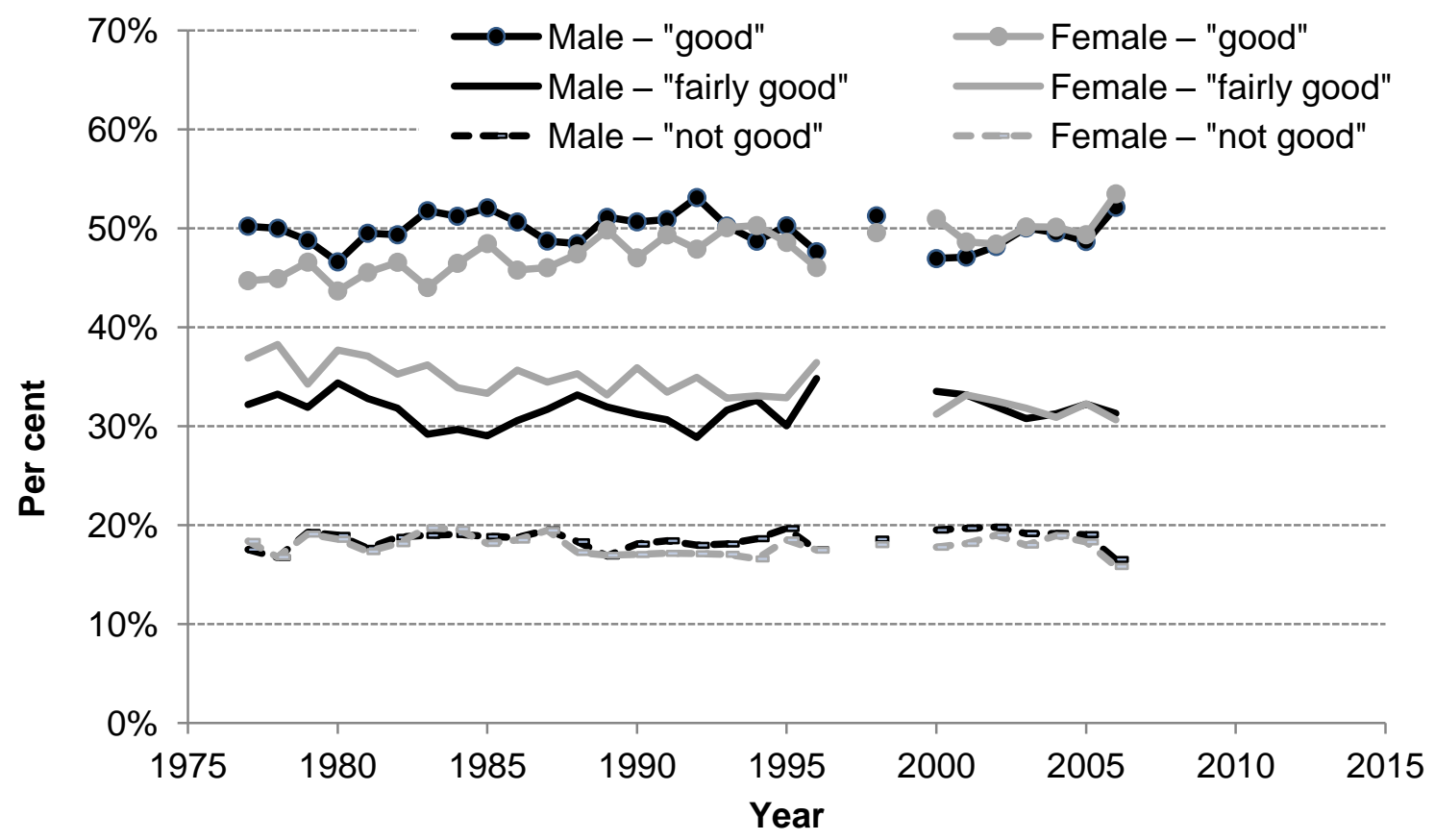

Such a trend, or lack of trend, in self-reported health might seem at odds with such large and rapid improvements in life-expectancy and reductions in mortality rates for older working-age cohorts over the period. The measurement of health and disability trends across cohorts is a huge field of research and it uses various data and methodologies to try and investigate such issues. Whilst there is no consensus to date on exact trends in the UK, it seems clear that at least some of the extension in longevity has been healthy, but at the same time there has probably also been some increase in the length of life spent with disease and disability (particularly at older ages). For example, a recent paper calculated that, of the 2.1 year increase in life expectancy of men aged 65 that has occurred over the period 2000-02 to 2009-2011, 1.2 years has been an increase in years of 'good' health and 0.9 years has been an increase in years spent with 'not good' health. ${ }^{4}$

In order to try to examine the consequences of this for employment rates, in previous work we looked at various methods aiming to compute the health capacity to work and how it might have changed over time (Banks, Emmerson and Tetlow, 2016) using either time-series variation in mortality, or cross-sectional variation in health conditions and disability indicators as a basis for the

\footnotetext{
${ }^{4}$ Government Office for Science, July 2016, 'Future of an ageing population', Ref: GS/16/10 https://www.gov.uk/government/publications/future-of-an-ageing-population)
} 
calculations. In summary, this suggested that there was substantial capacity to work amongst the 5569 year old population, if one was willing to measure capacity to work purely in health terms.

Without more definitive data to summarise or quantify this further we leave the issue here, other than to say that, whatever the cohort trends in health have been, it seems unlikely that they have been a constraint that has been driving employment rates. One caveat to that is that most analysis has looked at health trends on average, or rates of health conditions and disabilities calculated for the population of older workers as a whole. If the focus were just on the low-educated (as some of our analysis will be in what follows) then, given what we know about the education health gradient, it might be more important to factor in any education-group specific trends for health and disability. This is left as a topic for future research.

So far we have seen that for men retirement ages are lower than they used to be, while longevity has increased and years of schooling has also increased. Such trends have an immediately apparent impact on the proportion of life individuals spend in the labour market. Banks and Smith (2006) compared men born in 1900 to those born in 1935 and showed that average school leaving ages rose by 1.8 years, median retirement ages fell by 4 years while life expectancy at age 55 rose by 2.2 years. As a result the proportion of life spent not working (either as a result of school or retirement) increased from $30 \%$ to $40 \%$. Despite increased retirement ages across later cohorts the continued increases in schooling and longevity suggest this is unlikely to have been reversed and may well have increased further.

\section{Trends in detail}

So far we have documented the trends in employment rates of men and women over time and shown how this varied across different age groups and the extent to which, for those approaching the state pension age, the story changes when accounting for rising levels of education over time among those approaching retirement. In this section we examine these trends in more detail.

We start by describing differences in employment rates by age for different birth cohorts. Again we do this separately for men and women. We then turn to examine how these have varied for those with relatively low or high levels of education. Finally we describe differences in trends in employment into different occupations and how growth in wages has varied between different age groups. Throughout we highlight policy reforms, and other changes to financial incentives to retire, which may help explain the trends that we see.

\subsection{Trends in employment: a birth cohort analysis}

Differences in male employment rates, by age and decade of birth, are shown in Figure 3.1. At older ages two clear differences in employment rates between the different birth cohorts can be seen.

First, as expected, there is a much greater rate of employment between ages 50 and 59 among those born in the 1920s (with the bulk of these data relating to the late 1970s and the early 1980s) than for those born in the 1930s, 1940s, 1950s and - as far as can be seen in the available data so farthose born in the 1960s. Second, while male employment rates decline sharply with age as individuals move through their late 50s and early 60s, this decline was much sharper among those born in the 1920s and, albeit to a lesser extent those born in the 1930s, than it was among those born in later decades. The combination of these two features means that while those men born 
during the 1940s were less likely to be in paid employment when they were aged between 50 and 59 than those born in the 1920s or 1930s, they were more likely to be in paid employment during their late sixties than those born in the previous two decades.

Finally the figure also shows that employment rates at younger ages fell dramatically between those born in the 1950s and those born in the 1970s, with the main counterpart to this being the expansion of higher education over this period. While not relevant for this study of employment rates of older workers over the period since the mid-1990s, given that those with higher levels of education are currently more likely to be in paid work at older ages than those with lower levels of education (as shown in the previous section) this might be expected to boost employment rates of older men in the future.

Figure 3.1 Employment among successive cohorts of men

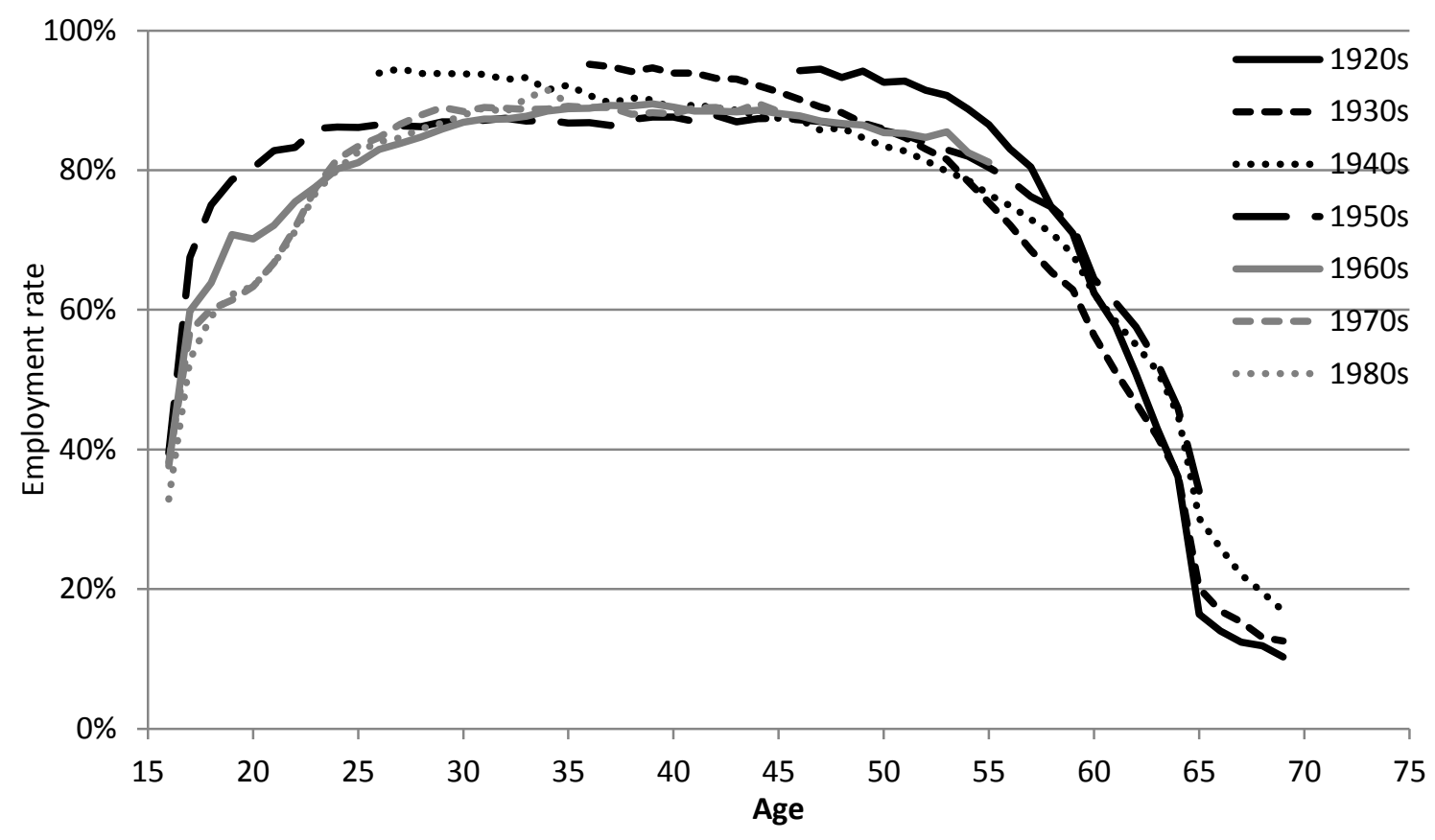

Source: Labour Force Survey.

This shift to a more gradual decline in employment rates by age among older men is likely to have, in part, been brought about by policy reforms and other changes affecting the financial incentives to retire at particular ages faced by older workers. Most obviously the abolition of the earnings-test on the state pension in the late 1980s has been found to have increased the labour supply of men aged 65 to 69 (Disney and Smith, 2002). The shift among private sector employers to providing defined contribution rather than defined benefit pensions will also have reduced the financial incentive to retire at a Normal Pension Age rather than at earlier or later ages (Blundell, Meghir and Smith, 2002). Finally the shift from Invalidity Benefit (IVB) to Incapacity Benefit (IB), from April 1995, was designed to reduce the on-flow onto incapacity benefits and may have improved financial incentives to work among many of those who might otherwise have been able to qualify for IVB.

The equivalent data for women are presented in Figure 3.2. This also shows that there has been a big shift in employment rates at older ages across some successive birth cohorts and also a significant difference in how employment rates vary between, roughly, ages 20 to 35 . 
First, looking at employment rates of women in their early fifties these were much higher among those born in the 1950s than among those born in the 1940s, 1930s or 1920s. Rather than leading to a faster drop in employment rates at later ages this appears largely to have fed through into larger employment rates among women from more recent birth cohorts in their late fifties and early sixties. So this suggests that a big part of the rise in employment rates at these older ages is explained by women reaching older working ages with greater attachment to the labour market. So reforms - and other changes - affecting financial incentives to retire are most likely a smaller part of the overall story for women than for men. Looking forwards women born in the 1960s appear to have had slightly higher employment rates in their early fifties than those born in the 1950s did at the same ages. This might suggest we can expect a further - albeit slight at least relative to the large increases seen recently - further increase in employment of women in their late fifties over the next few years.

\section{Figure 3.2 Employment among successive cohorts of women}

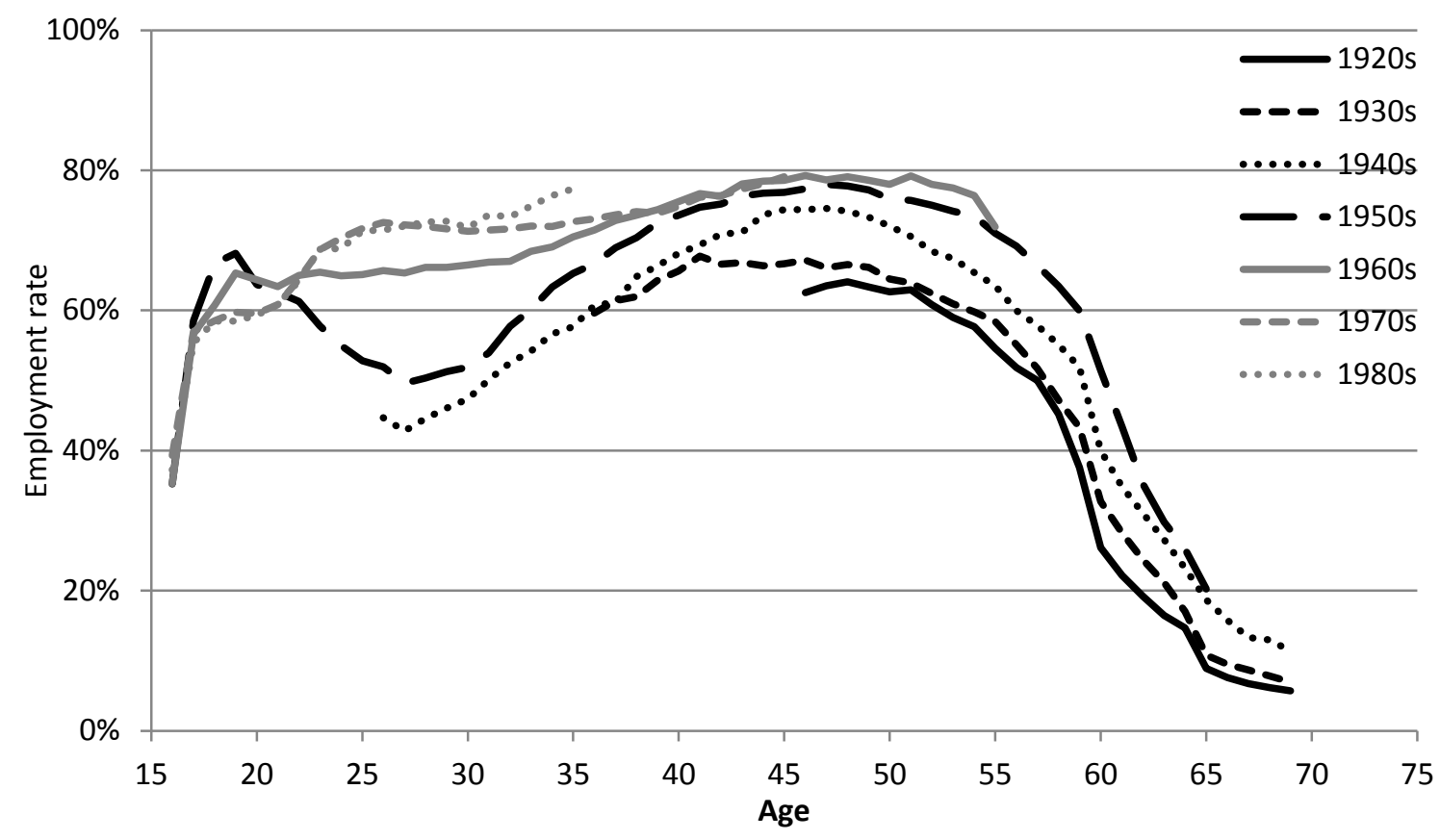

Source: Labour Force Survey.

The other big difference between employment rates of women from different birth cohorts can be seen during child bearing ages. For those born in the 1950s employment rates of women fell from two-thirds during late teens, to half at age 27 , before rising again so that they had returned to just two-thirds by age 37. In contrast there was no noticeable dip in employment rates of women during their twenties among those born in the 1960s and 1970s. This may well have implications for employment outcomes of older women in future. As noted above the employment rate of women in their early fifties who were born in the 1960s is only slightly above what it was at the same age among women born in the 1950s, potentially suggesting only a relatively limited increase in employment rates going forwards. But because they were more likely to have been in paid work through their 20s and 30s these women will, on average, have a greater amount of accumulated labour market experience than previous generations of women had at the same ages. This might help boost their employment prospects at older ages - not just in terms of their employment rate, 
but potentially their hours of work and their hourly wage. Whilst not directly related to the retirement analysis here, Blundell, Costa Dias, Meghir and Shaw (2016) provide a detailed analysis and structural modelling of female life-cycle labour market participation and its relationship to education choices, childbearing and the incentives in the welfare system.

Where there is strong evidence of policy reforms affecting the retirement behaviour of women is from the rise in the state pension age for women from age 60 in April 2010. This increases the age at which women can (and in the vast majority of cases do) receive a state pension although it does not, at least overall, lead to an obvious change in financial incentives to be in paid work because there is no requirement to retire in order to claim a state pension and no ability to draw a state pension before the state pension age. Exploiting the fact that the state pension age has been increased gradually - and therefore in any time period there is variation in the state pension age between women born not that far apart - Cribb, Emmerson and Tetlow (2016) find that increasing this age led to a 6.3 percentage point increase in the rate of employment between the old and new state pension age. Descriptive evidence on this - using the same data as utilised by Cribb et $a l-$ is presented in Figure 3.3 which shows the employment rate by single year of age among women aged 56 to 63 over time. Employment rates are generally higher for younger women than older women, and prior to 2010 tended to increase gradually over time among women of all ages. Marked in black are the employment rates over the window where the state pension age was increased from one age to the next. It is clear from the figure that these periods were associated with particularly rapid increases in employment, both relative to what happened among women of that same age before and after the reform was implemented, but also when compared to what was happening to the employment rate of younger and older women at the same point in time.

Figure 3.3 Employment rate among women, by single year of age as state pension age rises

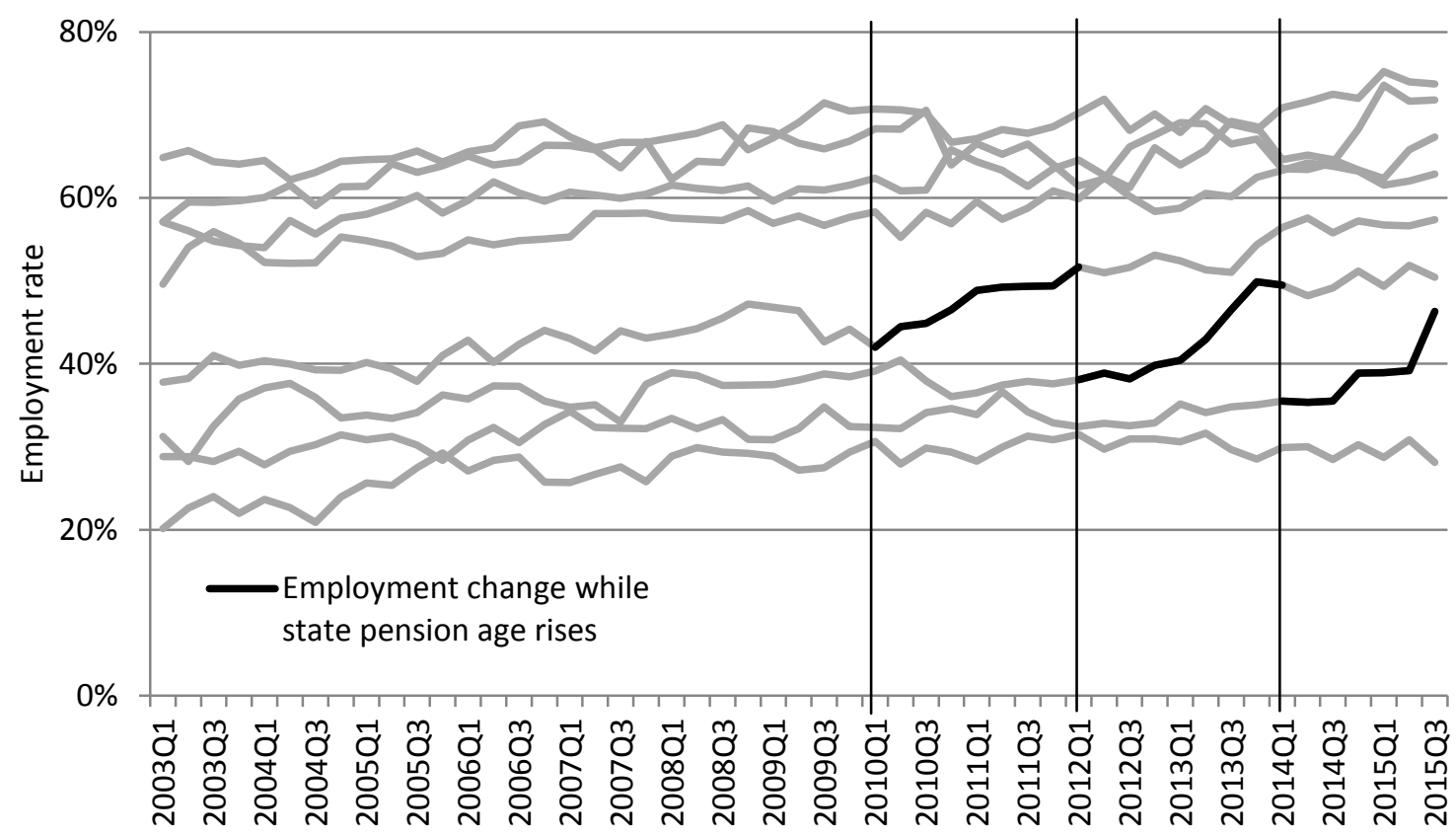

Source: Labour Force Survey.

Finally, we show how employment rates by age for different birth cohorts have varied by the level of education. This analysis is carried out using the same "high" and "low" education groups (i.e. 
excluding the "mid" education group) as defined in the previous section. Figures 3.4 and 3.5 present the data for low and high education men, respectively. The two features seen in the aggregate male cohort profiles above - that employment rates during ages 50 to 59 have fallen sharply from those experienced by those born in the 1920s, and that the employment rate of older men now declines more gradually at older ages than it did for those born in the 1920s - are particularly pronounced for those with low levels of education and less visible for those with high levels of education. So these two features of the aggregate profile are not consequences of increasing levels of education over the period, and are mainly driven by changes across birth cohorts amongst those with lower levels of education. This suggests the investigation of institutional explanations for such changes in employment at older ages (as opposed to economic explanations such as wealth effects or changes in employer demand for certain types of skills) might focus initially on looking at programmes or retirement institutions where changes have impacted differentially on different education groups. Examples might be the changing incentives in disability benefits, or perhaps the role of cohort changes in the balance (and rules) of DB versus DC pensions.

Figure 3.4 Employment among successive cohorts of low educated men

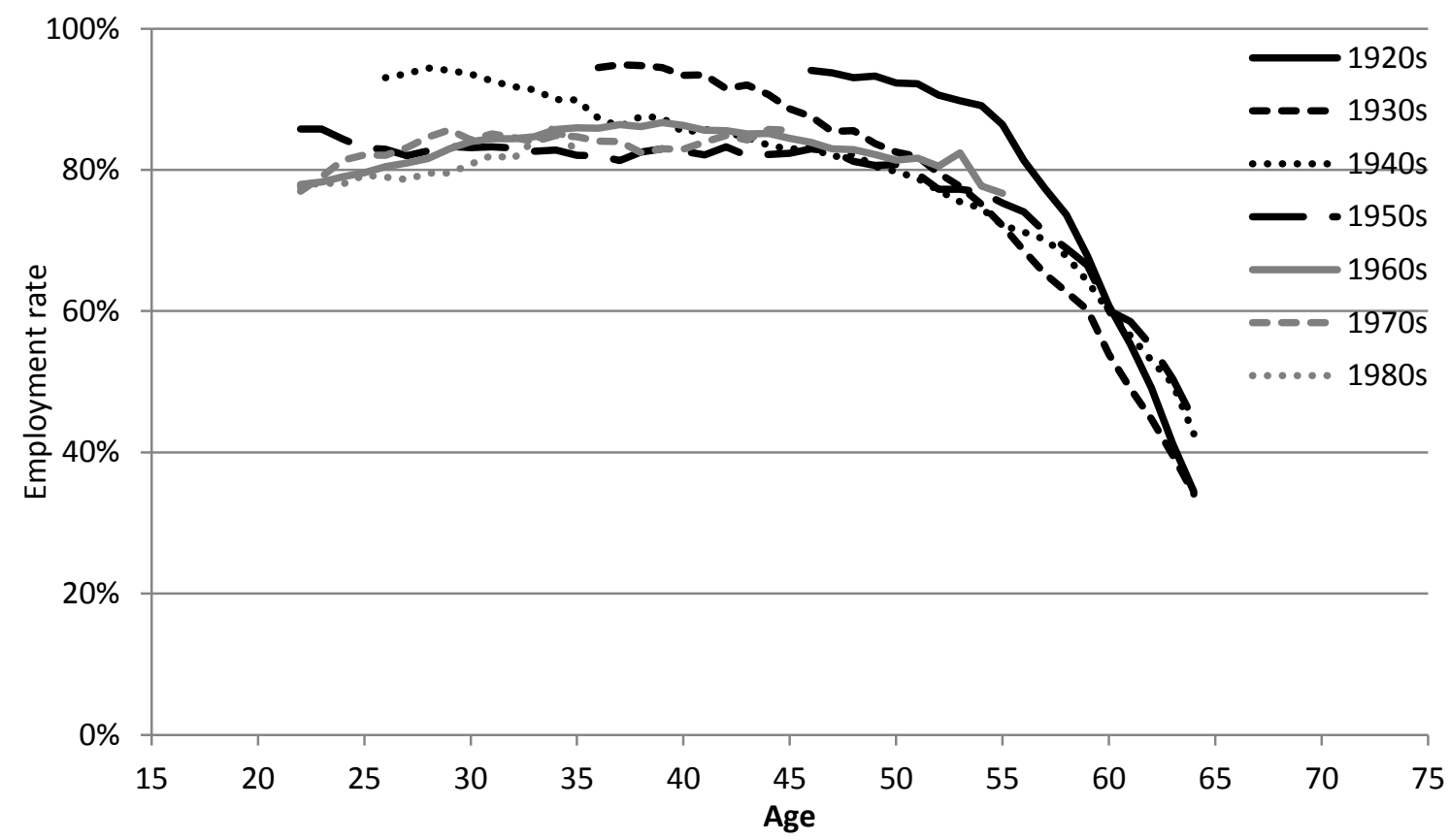

Source: Labour Force Survey. 
Figure 3.5 Employment among successive cohorts of high educated men

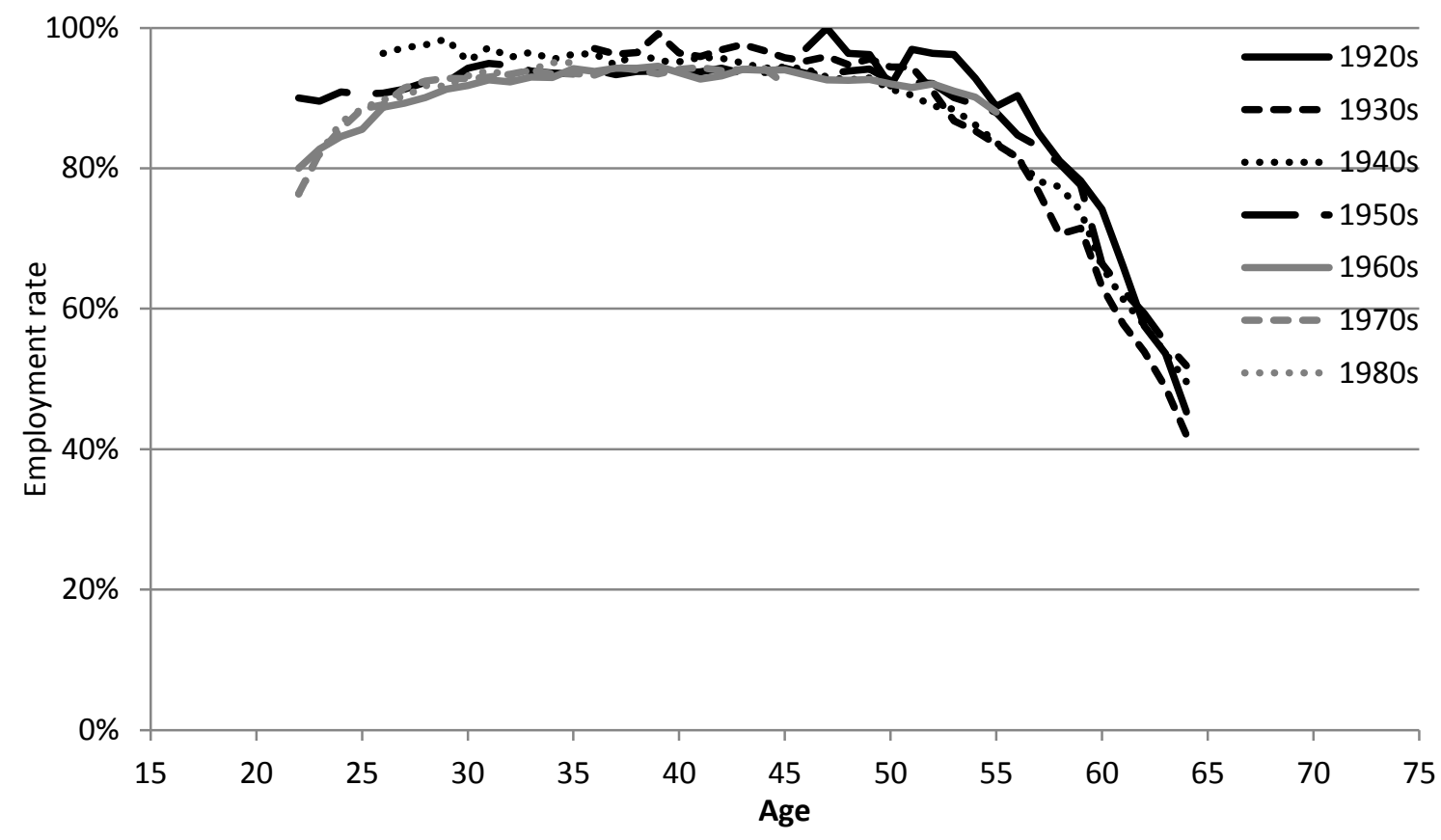

Source: Labour Force Survey.

The equivalent statistics for women are presented in figures 3.6 and 3.7. In general, employment rates of high educated women are greater than those of low educated women. In contrast to the story for men, the aggregate cohort patterns presented in Figure 3.2 can be seen both among those with low levels of education and also among those with high levels of education. First, in both cases employment rates of women in their early fifties these were much higher among those born in the 1950s than among those born in the 1940s, 1930s or 1920s. Second, while there is a dip in the employment rates during childbearing years among those born in the 1960s and 1970s this is much less noticeable than it is among those born in the 1950s. In both of these cases the changes across birth cohorts are more pronounced among those with higher levels of education.

In terms of the outlook for the employment prospects of women in their sixties going forwards two things look likely from these figures. First, the slightly higher employment rate of women in their early fifties who were born in the 1960s compared to the 1950s is only present for women with low levels of education. This suggests that the "birth cohort effect" boosting the employment rate of women in their sixties in the near future might be driven by an increase in employment among women with low (as opposed to high) levels of education. Second, the fact that women in their sixties will increasingly have accumulated greater labour market experience over their entire lifetimes is especially true for women with high levels of education since it is among this group where employment rates during late 20s/early 30s have increased the most. This could be particularly likely to boost the future wages of older women given the evidence that wage returns to labour market experience (and the negative returns to time out of the labour market) are stronger for women with higher rather than lower levels of education (Costa Dias, Elming and Joyce, 2016). 
Figure 3.6 Employment among successive cohorts of low-educated women

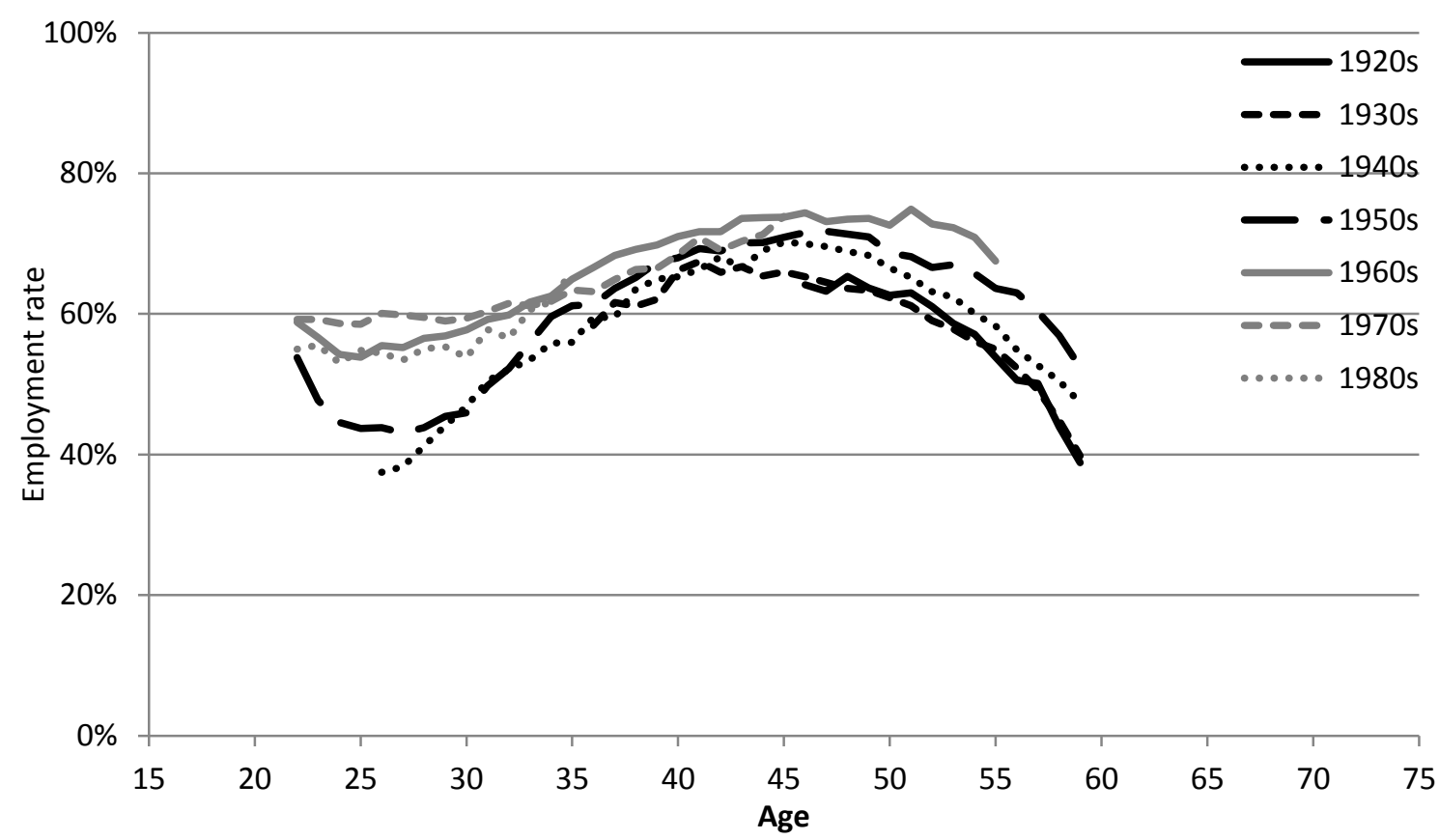

Source: Labour Force Survey.

Figure 3.7 Employment among successive cohorts of high-educated women

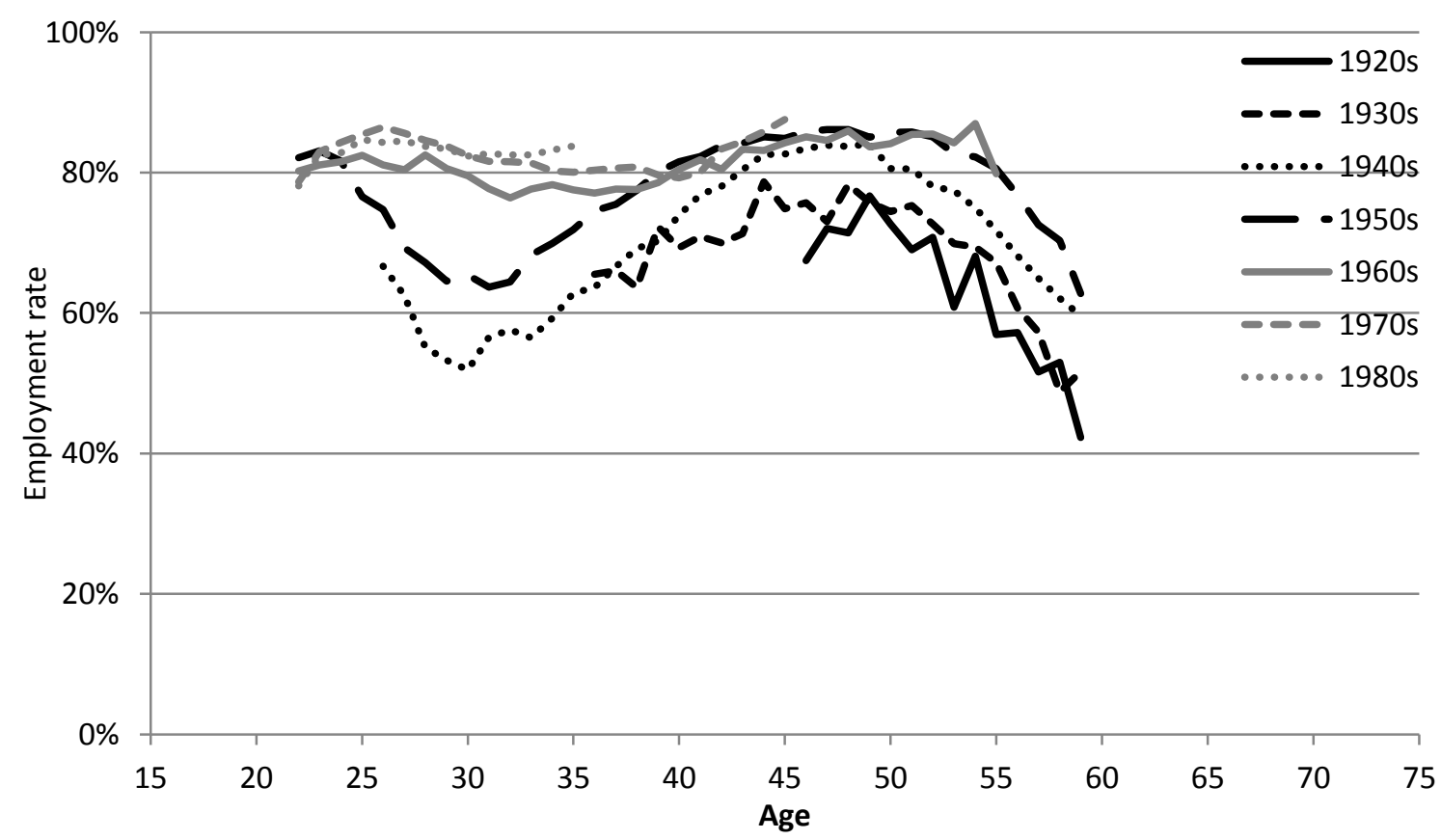

Source: Labour Force Survey. 


\subsection{Employment trends by occupation}

In what follows we look at employment rates in different occupations over time and, in particular, at the extent to which the trends seen among older individuals over the period since 1995 are similar to, or divergent from, those seen among young working age individuals. Specifically the per cent of individuals aged 50 to 64 who are employed in a particular occupation - and how this has changed over time - is compared to the equivalent among individuals aged 20 to 49 . Again this is done separately by sex. Three broad occupational groups are considered: first, professional, managerial or technical; second, skilled non-manual; third, skilled manual.

Summary data on employment in professional, managerial and technical occupations are presented in Figure 3.8. Over the twenty years from 1995 to 2015 the per cent employed in these areas increased among older men, younger men, older women and younger women. While these increases were very large for those aged 20 to 49 (at 4.7ppt and 11.2ppt for 20 to 49 year old men and women, respectively) the equivalent increases seen over the same period for men and women aged 50 to 64 are even larger (8.7ppt and 13.6ppt, respectively). As a result the employment gap in these occupations between older and younger individuals - seen among both men and women - is now considerably smaller than it was twenty years ago. So this is an area where employment growth has generally been favourable in the UK over the last twenty years, but that the increase in the employment rate has been greater for older individuals than for younger individuals.

Figure 3.8 Percentage of older and younger individuals employed in professional, managerial or technical occupations over time, by sex

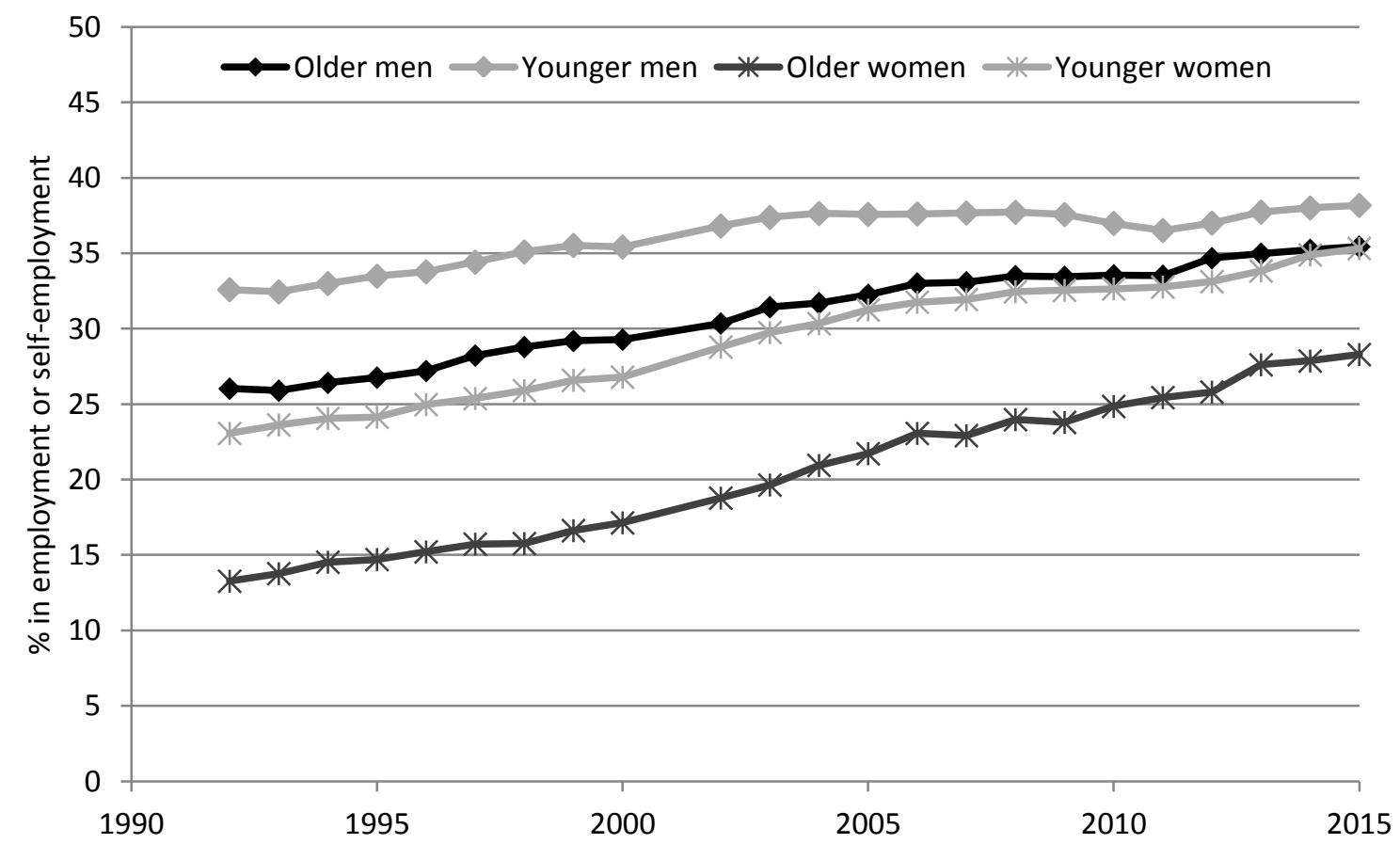

Note: "Older" contains those aged 50 to 64 and "Younger" contains those aged 20 to 49.

Source: Labour Force Survey.

The equivalent data for employment in skilled non-manual occupations are shown in Figure 3.9. Among men the employment rate over the period since the mid 1990s in these occupations has been broadly stable and this is true both among men aged 50 to 64 and among men aged 25 to 49 . 
Among women there is a striking difference in the trends by age. Among those aged 50 to 64 the employment rate of women in these occupations was greater in 2015 than in 1995, with the decline in employment since 2003 not being sufficient to offset the earlier growth. In contrast the percentage of women aged 20 to 49 employed in skilled non-manual work has declined throughout this period. So, among women, this is an area where employment growth among those aged 50 to 64 , albeit slight, has occurred despite employment in these occupations becoming less common among younger women.

Figure 3.9 Percentage of older and younger individuals employed in skilled non-manual occupations over time, by sex

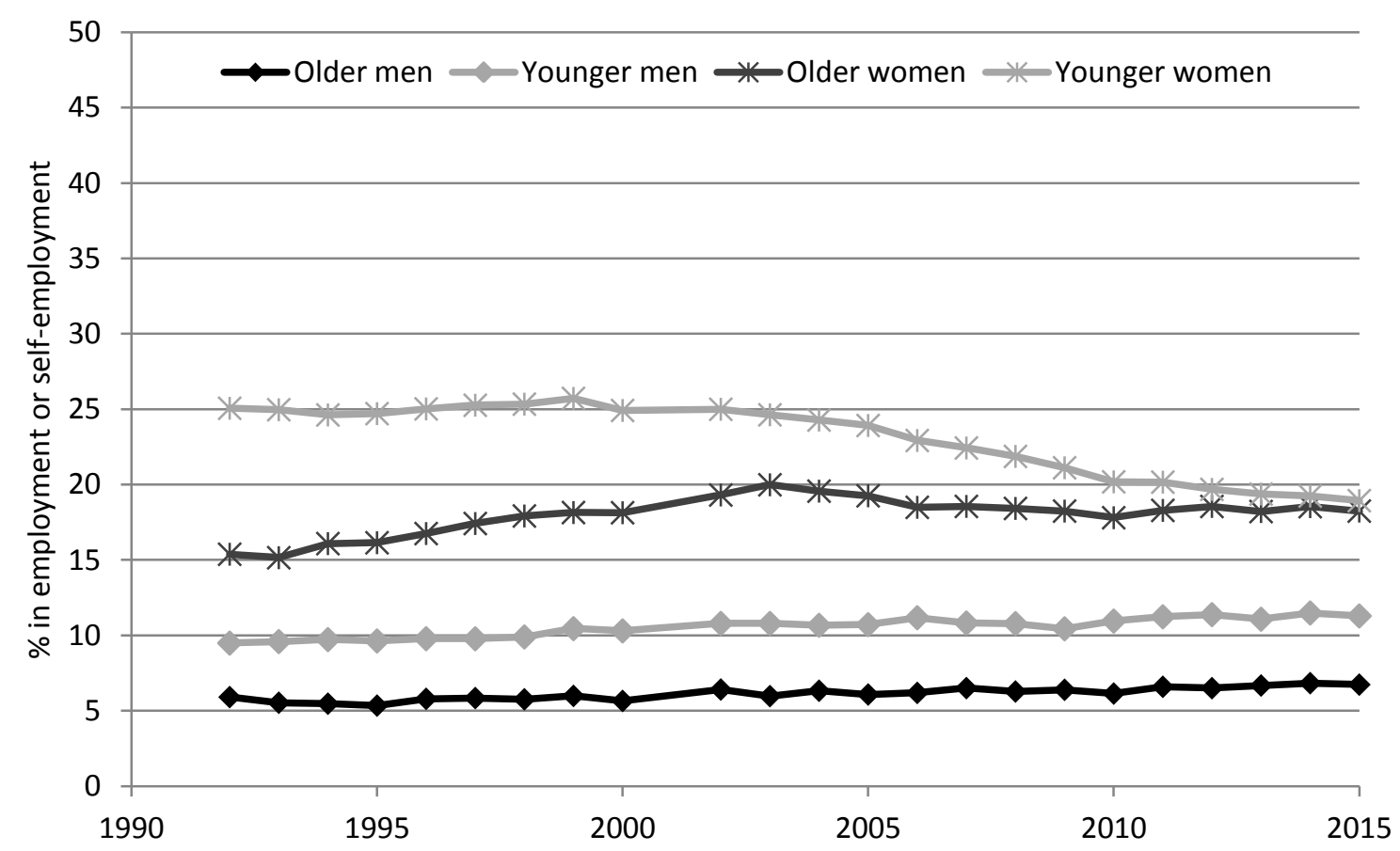

Note: "Older" contains those aged 50 to 64 and "Younger" contains those aged 20 to 49.

Source: Labour Force Survey.

Finally the patterns for employment in skilled manual occupations are presented in Figure 3.10. This shows that over the period since 1995 there is little change in the proportion of older men, or older women, who are employed in skilled manual occupations. This is also true of younger women - but despite a reasonably sharp fall (of almost $4 \mathrm{ppt}$ ) in the percentage of younger men who are employed in skilled manual occupations. So this is an area where the employment rate of older men (and older women) has held up despite a fall in the employment rate in these occupations among younger men. 
Figure 3.10 Percentage of older and younger individuals employed in skilled manual occupations over time, by sex

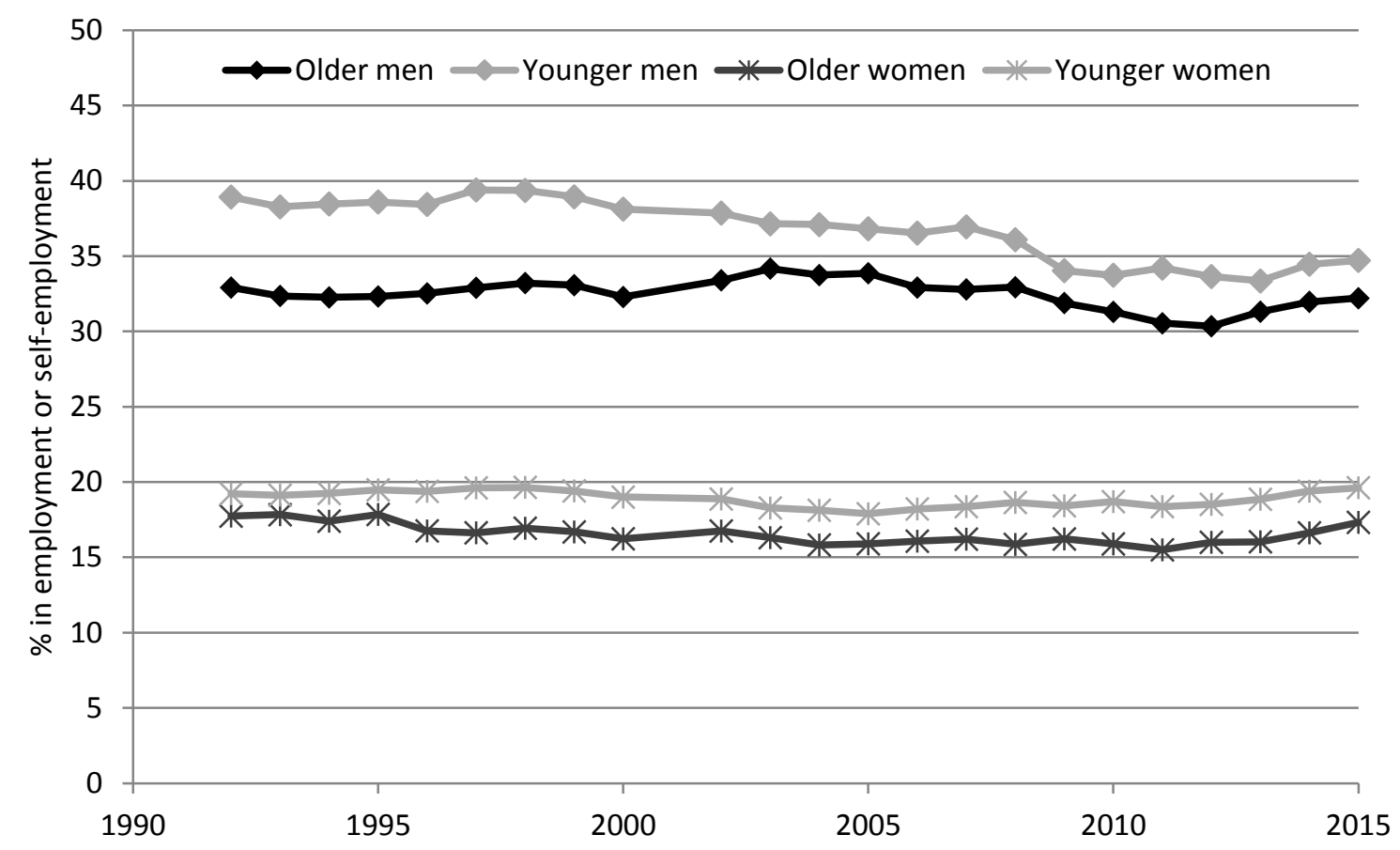

Note: "Older" contains those aged 50 to 64 and "Younger" contains those aged 20 to 49.

Source: Labour Force Survey.

\subsection{Wage growth among older workers}

The focus so far has been on trends in employment - both overall and in different types of occupations. This subsection looks instead at the evolution of average hourly wages among older employees and compares these to both inflation and hourly wage growth among younger employees. This is of interest both because it can show how part of the financial incentive to be in paid work (the wage) is evolving and also because changes in the observed wage distribution over time for different age groups are informative about the characteristics or skills of the individuals who are choosing to remain in paid work.

The data on growth in median hourly wages among men are presented in Figure 3.10, with wages indexed to 100 in 2005. Between the mid 1990s and 2003 there was broadly similar growth in hourly wages between different age groups of men, and all age groups enjoyed wage growth that exceeded inflation, with those aged 65 to 69 experienced slightly higher wage growth than younger age groups. A more diverse pattern can be seen over the period since 2003, with average male wage growth being greater among older age groups than among younger ones. While male wage growth among 65 to 69 year olds and, albeit to a lesser extent, 55 to 64 year olds has continued to outstrip inflation the period since 2003 has seen average male wage growth among 20 to 29 year olds, 30 to 39 year olds and 40 to 54 year olds of less than the rate of inflation. 
Figure 3.10 Median wages of men, over time, by age group

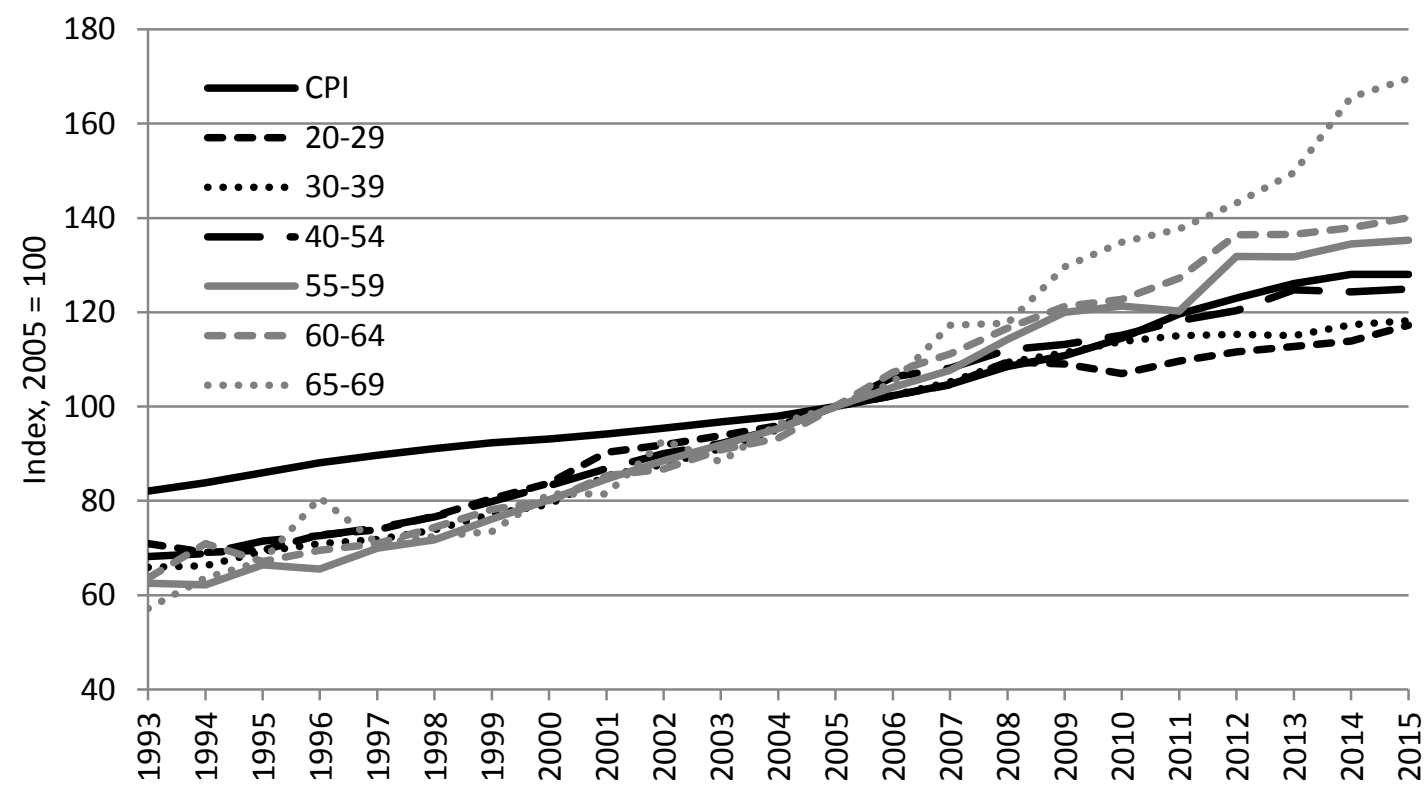

Source: Labour Force Survey.

Trends in hourly wages, by age group, among women show a fairly similar story to those for men. Over the period from the mid 1990s to 2003 all age groups experienced wage growth in excess of inflation, with not that much dispersion in wage growth between different age groups. Over the period from 2003 to 2015 there is more dispersion in wage growth between different age groups with, as there was for men, greater average wage growth among older employees than younger ones. Although, unlike men, it is only 20 to 29 year olds women who, as a group, have experienced wage growth which has been lower than the rate of inflation.

Figure 3.11 Median wages of women, over time, by age group

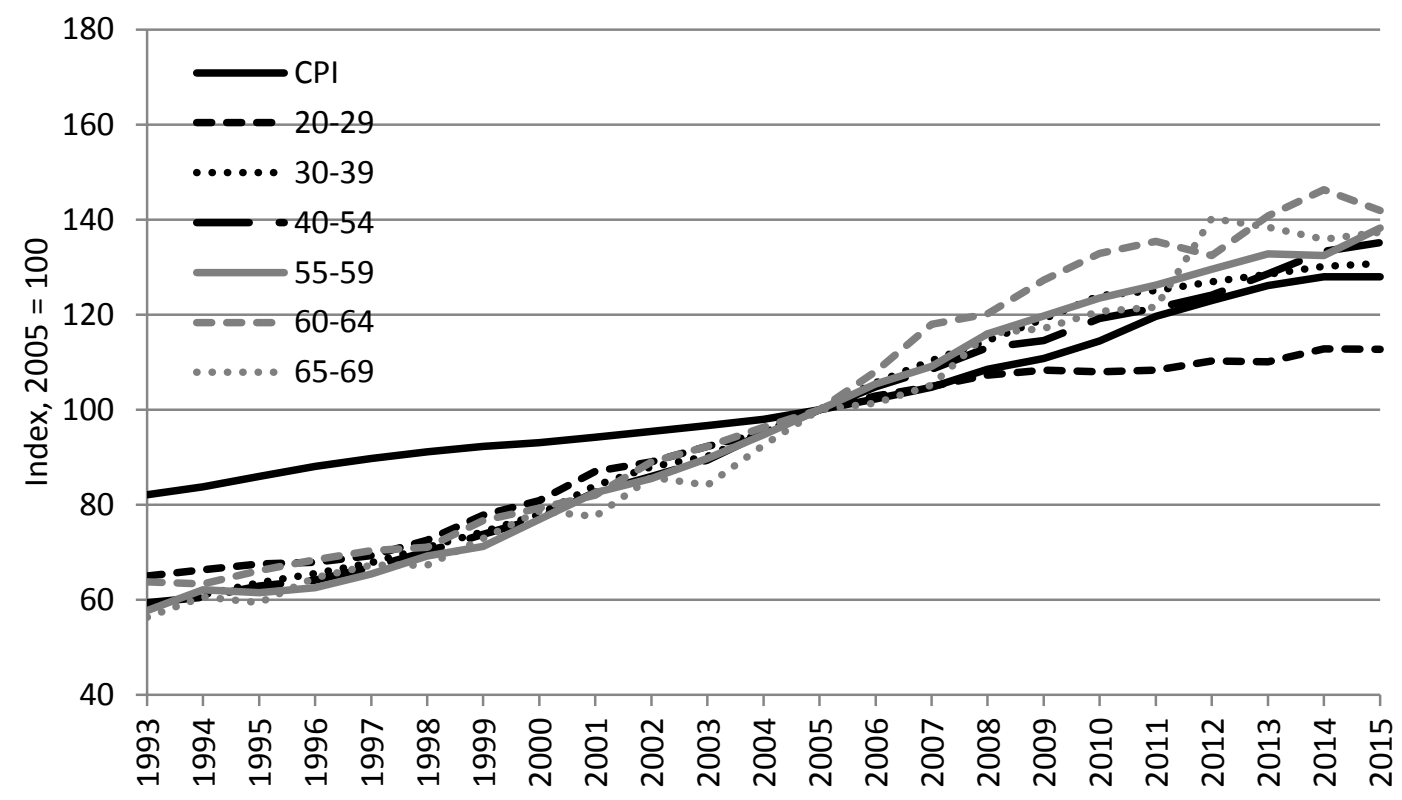

Source: Labour Force Survey. 


\section{Conclusions}

This paper has documented employment rates among older men and women over the forty years from 1975 to 2015. Over the first two decades of this period employment rates of older men fell, whereas over the subsequent two decades they rose. In contrast, employment rates of older women were relatively stable over the first decade but have risen sharply since and are now at record levels. The growth in employment of older men and women since the mid 1990s has coincided with a period of increases in the employment rate among younger men and women. In both cases, however, the growth in employment among older individuals over the last twenty years has been stronger than that of the rest of the working age population.

There have also been differences in these trends by education levels. When taking years of schooling as a measure of educational attainment employment rates of older men over the period since 1995 have grown much faster among the "low educated" than among the "high educated". As a result the gradient in employment among men by education is much less steep than it used to be, with employment rates among "low educated" men now higher than they were in the mid 1970s. In contrast, growth in the employment rate among older women has been similar across the education distribution. But, as we have documented, there are some not insubstantial issues with using years of schooling as a measure of education, not least because a large proportion of men who left school at age 15 (or earlier), and therefore without any formal qualifications, have subsequently acquired some. And when using qualifications, rather than years of schooling, as a measure of education suggests that a much larger proportion of the increase in employment rates of older women over the period since 1995 can be accounted for by rising education levels across successive birth cohorts.

Of key interest to policymakers is the extent to which reforms have contributed to changes in employment rates that we have documented. In terms of state pensions there have been many significant reforms over the period since 1975 , though many will have had a limited impact on the marginal financial incentive to retire that individuals face. The most important being, perhaps, the removal of the earnings test from 1989 which research has shown increased employment among men aged 65 to 69 (and will have also limited the extent to which subsequent reforms affected the incentive to work) and the increase in the female state pension age since 2010 which has also been shown to have boosted employment rates of those women who as a result now cannot receive a state pension until later. Further rises in the female state pension age - and, from 2018, the male state pension age - are likely to push employment rates of older women and men up further. Other policy reforms since the mid-1990s may have also have had important impacts on employment outcomes, not least the reforms to incapacity benefits in 1995 and 2008, and the more recent outlawing of mandatory retirement ages. A more explicit investigation of the role of these reforms in explaining the overall trend, perhaps in comparison with what has been occurring in other countries over the same time period, is left as an important topic for future research.

It is also clear that the story behind the changes in employment rates cannot fully be told by looking at policy reform alone. Other trends will have been important. Among older men - and in particular "low educated" men - we have shown that employment rates at older ages now decline more gradually than they did in the past and this, at least in part, is likely to have been brought about by the shift among private sector employers from providing defined benefit pensions to providing 
defined contribution pensions. This shift is likely to continue having an effect on retirement behaviour for some time as will, eventually, the reforms to public-service pensions that came into effect in the mid 2000s (for new entrants) and the mid 2010s (for all members more than ten years from their existing normal pension age).

Among women differences in employment rates at younger ages are a key part of the story. Women born in the 1950s had much higher employment rates in their early fifties than those born earlier, and this has fed into an increased employment rate at older ages (rather than a faster drop in employment rates in their mid fifties). Among those women born in the 1960s there has been, at least among those with 'low' education, a further increase in employment in their early fifties suggesting that continued increases in employment rates of older women are likely. In addition employment rates among women at younger ages - in particular among women with higher levels of education - mean that over time women are approaching their sixties with greater labour market experience potentially boosting the wage that they can command (particularly given the evidence that wage returns to labour market experience are stronger for women with higher rather than lower levels of education) which, in turn, could also encourage them to remain in the labour market for longer.

Economy-wide trends - such as the shift away from physically demanding jobs in primary industry and manufacturing towards service sector roles - might well have affected employment rates at older ages. And as we have shown the proportion of older men and women employed in professional, managerial and technical occupations has been particularly strong, outstripping even the strong growth in the employment rate in these roles seen among younger individuals. At the same time we have seen an increase in relative wages of older workers that has been particularly apparent for those aged 65 and over. This is a trend which is likely to be related to selection effects as retirement incentives evolve, but also by cohort effects in education and life-time occupational choices feeding through into the employment outcomes of older workers as each successive cohort moves through later life.

Further research - and indeed the attention of policymakers - should be focussed not solely on whether or not older individuals are working but consider more the nature of their activities in paid work as well as considering hours worked and earnings as these will all be key determinants of the living standards of older individuals and are likely to have been changing systematically over time as the pattern of employment participation at older ages evolves. 


\section{References}

Banks, J., Blundell, R. and Emmerson, C. (2015) 'Disability Benefit Receipt and Reform: Reconciling Trends in the United Kingdom', Journal of Economic Perspectives, Vol. 29, No. 2.

Banks, J., Emmerson, C. and Tetlow, G. (2016) 'Effect of Pensions and Disability Benefits on Retirement in the United Kingdom' p. 81-136 of Wise, D. A. (ed.), Social Security Programs and Retirement Around the World: Disability Insurance Programs and Retirement, National Bureau of Economic Research: University of Chicago Press.

Banks, J., Emmerson, C. and Tetlow, G. (2017), 'Health Capacity to Work at Older Ages: Evidence from the United Kingdom' p. 329-357 of Wise, D. A. (ed.), Social Security Programs and Retirement Around the World: The Capacity to Work at Older Ages, National Bureau of Economic Research: University of Chicago Press.

Banks, J. and Smith, S. (2006), 'Retirement in the UK', Oxford Review of Economic Policy, vol. 22, no. 1, pp. $40-56$.

Blundell, R., Costa Dias, M., Meghir, C. and J. Shaw (2016), 'Female Labor Supply, Human Capital, and Welfare Reform', Econometrica, Econometric Society, vol. 84, pages 1705-1753, 09.

Blundell, R, Meghir, C. and Smith, S. (2002), 'Pension Incentives and the Pattern of Early Retirement', Economic Journal, 112, No.478, March, C153-C170.

Bozio, A., Crawford, R. and Tetlow, G. (2010), The history of state pensions in the UK: 1948 to 2010, IFS Briefing Note 105, London: Institute for Fiscal Studies.

Costa Dias, M., W. Elming and R. Joyce, (2016), The Gender Wage Gap, IFS Briefing Note 186, London: Institute for Fiscal Studies

Crawford, R., Keynes, S. and Tetlow, G. (2013) A single-tier pension: what does it really mean?, IFS Report R82, London: Institute for Fiscal Studies.

Cribb, J. Emmerson, C. and Tetlow, G. (2016) 'Signals matter? Large retirement responses to limited financial incentives', Labour Economics, vol. 42, p. 203-212.

Disney, R. and Smith, S. (2002) 'The labour supply effect of the abolition of the earnings rule for older workers in the United Kingdom', The Economic Journal, vol. 112, c. 136-152. 